Amsterdam Expeditions to the West Indian Islands, Report 64*

\title{
A new family of harpacticoid copepods and an analysis of the phylogenetic relationships within the Laophontoidea T. Scott
}

\author{
Rony Huys \\ Marine Biology Section, Zoology Institute, State University of Gent, K.L. Ledeganckstraat 35, B-9000 Gent, \\ Belgium; and Delta Institute for Hydrobiological Research, Vierstraat 28, 4401 EA Yerseke, \\ The Netherlands
}

Keywords: Cristacoxidae fam. nov., Cristacoxa gen. nov., Cubanocleta, Noodtorthopsyllus, Laophontoidea, phylogeny, Copepoda

\section{Summary}

A new family Cristacoxidae is proposed to accommodate the monotypic genera Cristacoxa gen. nov., Noodtorthopsyllus Lang (ex Canthocamptidae) and Cubanocleta Petkovski (ex Laophontidae). Cristacoxa petkovskii gen. et spec. nov. is described on the basis of a single male collected from coralline sand of Bonaire, West Indies. N. psammophilus Noodt and $C$. noodti Petkovski are redescribed and refigured on the basis of new material from the Galápagos (Isla Santa Cruz), the West Indian Islands (Curaçao, Klein Curaçao, Bonaire) and the Canary Islands (El Hierro, Tenerife). The new family is characterised by the presence of an outer spinous process on the first antennular segment, the absence of the antennary exopod, the uniramous mandibular palp, the presence of conspicuous cristae on the precoxa and coxa of leg 1 and the elongation of the apical exopodal spines of P2 to P4. The Cristacoxidae are unique in having an equal number of setae/spines on the P5 in both sexes. Examination of the ontogeny of this leg in males and females of Orthopsyllus spec. gives strong evidence that the cristacoxid P5 has undergone neotenous evolution. Males of Cristacoxidae are readily recognisable by their extremely long spermatophores. The new family is allocated to the superfamily Laophontoidea T. Scott, together with the Laophontidae T. Scott, the Laophontopsidae Huys \& Willems, the Orthopsyllidae Huys and the Adenopleurellidae Huys. A phylogenetic analysis of the relationships within the superfamily is presented, and as a result Por's (1986) concept of the Laophontoidea is refuted. Instead, it is concluded that the superfamily can be defined on the basis of the following apomorphies: (1) antennules with outer spinous process on segment 2; (2) antenna with allobasis bearing 1 seta; (3) antennary exopod quadrisetose; (4) Pl exopod without inner seta on exp-2 and 4 setae/spines on exp-3; (5) P1 endopod 2-segmented with elongated enp-1 and 2 elements on enp-2; (6) P2-P4 with 2-segmented endopods; exp-1 without inner seta;
(7) sexual dimorphism of P3 endopod; (8) P6 bisetose with one member fused to somite. There is no close relationship neither with the Normanellidae Lang, nor with the Ancorabolidae T. Scott. The Laophontidae are considered the first of fshoot in the evolution of the Laophontoidea because of the retention of the 8-segmented antennule in both sexes and the ancestral seta formulae on P2-P4. The other families can be assigned to two clades: the Adenopleurellidae and the Laophontopsidae-Cristacoxidae-Orthopsyllidae-grouping. The Laophontopsidae and the Cristacoxidae are sister groups because of the shared sexual dimorphism of the P3 endopod (advanced type), and the fusion of antennular segments distal to the geniculation in the male. Emphasis is placed on the postembryonic development in the Laophontoidea of the male P3 endopod and P6 and on their homologies in the female. A reconstruction of the hypothetical ancestor of the Laophontoidea is presented.

\section{Zusammenfassung}

Um die monotypischen Gattungen Cristacoxa gen. nov., Noodtorthopsyllus Lang (ex Canthocamptidae) und Cubanocleta Petkovski (ex Laophontidae) unterzubringen, wird eine neue Familie Cristacoxidae vorgeschlagen. Cristacoxa petkovskii gen. et spec. nov. wird auf der Basis eines einzelnen Männchens beschrieben, das von Korallensand auf Bonaire, Westindische Inseln, gesammelt wurde. $N$. psammophilus Noodt und $C$. noodti Petkovski werden anhand neuen Materials von Galápagos (Isla Santa Cruz), den Westindischen Inseln (Curaçao, Klein Curaçao, Bonaire) und den Kanarischen Inseln (El Hierro, Teneriffa) neu beschrieben und neu illustriert. Die neue Familie ist charakterisiert durch das Vorhandensein eines äußeren Dornfortsatzes am ersten Antennulasegment, das Fehlen eines Exopoditen an der Antenna, den uniramen Mandibularpalpus, das Vorhandensein auffälliger Leisten (Cristae) an der Praecoxa

* Report 63 will be published in Beaufortia vol. 41 (1990). Contribution No. 455 of the Delta Institute for Hydrobiological Research, Yerseke. 
und Coxa von $P 1$ und die Verlängerung der apikalen Dornen an den Exopoditen von P2-P4. Die Cristacoxidae sind einmalig dadurch, daß P5 in beiden Geschlechtern die gleiche Anzahl von Borsten/Dornen trägt. Die Überprüfung der Ontogenie dieses Beines bei männlichen und weiblichen Individuen von Orthopsyllus spec. macht es sehr wahrscheinlich, daß P5 in den Cristacoxidae eine neotene Entwicklung durchgemacht hat. Männliche Cristacoxidae sind leicht an ihren extrem langen Spermatophoren zu erkennen. Die neue Familie ist zusammen mit den Laophontidae T. Scott, Laophontopsidae Huys \& Willems, Orthopsyllidae Huys und den Adenopleurellidae Huys der Superfamilie Laophontoidea T. Scott zugeordnet. Eine phylogenetische Analyse der Beziehungen innerhalb der Superfamilie wird vorgenommen und als deren Ergebnis Por's (1986) Konzept der Laophontoidea widerlegt. Statt dessen wird geschlußfolgert, daß die Superfamilie anhand folgender Apomorphien definiert werden kann: (1) Antennula mit äußerem Dornfortsatz am 2. Segment; (2) Antenne mit Allobasis, die eine Borste trägt; (3) Exopodit der Antenne mit vier Borsten; (4) Exopodit von P1 ohne innere Borste an exp-2 und vier Borsten/Dornen an exp-3; (5) Endopodit von P1 zweigliedrig mit verlängertem enp-1 und zwei Anhänge an enp-2; (6) P2-P4 mit zweigliedrigen Endopoditen; exp-1 ohne innere Borste; (7) Sexualdimorphismus bei Endopit P3; (8) P6 mit zwei Borsten, ein Bein mit dem Körpersegment verschmolzen. Weder zu den Normanellidae Lang noch zu den Ancorabolidae T. Scott gibt es enge Beziehungen. Die Laophontidae werden wegen der Beibehaltung der achtgliedrigen Antennula in beiden Geschlechtern und der ursprünglichen Borstenformel von P2-P4 als erste Abzweigung in der Evolution der Laophontoidea angesehen. Die anderen Familien können zwei Linien zugeordnet werden: den Adenopleurellidae und der Laophontopsidae-Cristacoxidae-Orthopsyllidae-Gruppe. Die Laophontopsidae und Cristacoxidae sind Schwestergruppen wegen des bei beiden vorhandenen Sexualdimorphismus des Endopodits von P3 (fortgeschrittener Typus) und der an der Antennula des Männchens distal von der Biegung vorhandenen Verschmelzung der Segmente. Besondere Bedeutung wird bei den Laophontoidea der postembryonalen Entwicklung des Endopodits von P3 und von P6 des Männchens und der homologen Teile beim Weibchen beigemessen. Eine Rekonstruktion des hypothetischen Vorfahren der Laophontoidea wird vorgestellt.

\section{Introduction}

The history of the genus Orthopsyllus Brady \& Robertson marks the course of a gradual recognition of the high variability in many of its morphological characteristics (Lang, 1965; Wells, 1968; Hamond, 1970) and the process of lumping together geographically widely separated populations into the inadequately described type species $O$. linearis (Claus, 1986) (cf. Boer, 1971). The diagnosis of the genus, however, was expanded considerably with the discovery of $O$. psammophilus by Noodt
(1955). This remarkable copepod, described from a coarse sandy beach on Tenerife, differs profoundly from the other species in many aspects (e.g. spinous process on different segment of antennule, absence of antennary exopod, ornamentation of swimming legs, P5 in both sexes) but Noodt (1955) attributed these differences to the "... stark abgeleitete und daher isolierte Stellung ..." of the species. Lang (1965) rightly concluded that $O$. psammophilus must have been splitted off before the evolution of the other Orthopsyllus-species, because the structure of the antennule and the armature of the second to fourth legs cannot be derived from the conditions found in the other members of the genus. Lang (1965) therefore proposed a new genus, Noodtorthopsyllus, to accomodate $O$. psammophilus as its type and only species. The new genus and its presumed relative Orthopsyllus were kept in the Canthocamptidae until Huys (in press c) removed the latter genus to a separate family.

The closest relative of $N$. psammophilus is without doubt Cubanocleta noodti Petkovski which is described from the mouth of the Rio Baconao in Cuba (Petkovski, 1977). According to Petkovski the absence of an antennary exopod combined with the structure of the rostrum, the thoracopods and the caudal rami suggests that $C$. noodti represents a link between the Ancorabolidae and the laophontid subfamily Normanellinae. He further recognised also a certain resemblance with some odd genera (Laophontella Thompson \& A. Scott; Apolethon Wells) of which the affinity to the Laophontidae was or is still doubtful.

A third closely related species was collected by Prof. Dr. J.H. Stock in coralline sand of Bonaire, Netherlands Antilles and is described herein as a new genus Cristacoxa gen. nov.. N. psammophilus and $C$. noodti are redescribed on the basis of material collected in the Galápagos (Isla Santa Cruz), the West Indian islands (Curaçao, Klein Curaçao, Bonaire) and the Canary Islands (Tenerife, El Hierro). Despite their laophontoidean relationships it is concluded that the three genera cannot be included in one of the existing families and therefore a new family Cristacoxidae fam. nov. is established to accommodate them.

The present paper is the final one in a series 
dealing with the relationships of various "laophontid-like" taxa (Huys, 1988a; in press a-c; Huys \& Willems, 1989). As a result of all these considerations a detailed phylogenetic analysis of the relationships within the superfamily Laophontoidea T. Scott is presented.

\section{Material and methods}

Specimens were dissected in lactic acid and the dissected parts were placed in lactophenol mounting medium. Preparations were sealed with glyceel (Gurr ${ }^{\circledR}$, BDH Chemicals Ltd, Poole, England).

All drawings have been prepared using a camera lucida on a Leitz Dialux 20 interference microscope. The terminology is adopted from Lang $(1948,1965)$ except for (1) the terms pars incisiva, pars molaris and lacinia mobilis, which are omitted in the description of the mandibular gnathobase (Mielke, 1984a), (2) the segmental composition of the mandible and maxilliped which are followed according to Boxshall (1985: 341-345). The setae of the caudal rami are named and numbered as proposed by Huys (1988b). Abbreviations used in the text and figures are: A1, antennula; A2, antenna; P1-P6, first to sixth thoracopods; exp., exopod; enp., endopod; exp(enp)-1(-2, -3$)$, to denote the proximal (middle, distal) segment of a ramus.

Type-material and other specimens are deposited in the collections of the Zoölogisch Museum, Amsterdam (ZMA) or retained in the personal collections of the author. The examination of Orthopsyllus sp. was based on material collected during the Belgian Expedition to the Australian Great Barrier Reef in 1967. Additional observations of Laophonte galapagoensis Mielke, Loureirophonte isabelensis Mielke, Afrolaophonte schmidti Mielke and Galapalaophonte pacifica Mielke were based on specimens collected by Prof. Dr A. Coomans during a working visit to the Galápagos.

\section{Taxonomy}

1. Cristacoxidae, a new family of interstitial harpacticoid copepods

Family CRISTACOXIDAE fam. nov.

Diagnosis. - Body cylindrical, no clear demarca- tion between prosome and urosome. First pedigerous somite fused to cephalosome. Epimeral plates of thoracic somites slightly developed. Cephalic shield with pattern of cuticular pits. Rostrum large and broad, completely defined at the base; with two sensillae and a ventral, subterminal tube-pore. Fusion of female genital double-somite demarcated by almost continuous internal, transverse, chitinous rib; and by surface ornamentation both laterally and dorsally. Anal operculum moderately developed; pseudoperculum absent. Caudal rami with numerous processes and 7 setae (seta $\mathrm{V}$ longest, sometimes bi-articulated). Sexual dimorphism in antennula, endopod P3 (outer seta of enp-2, when present, modified into an apophysis; 2 -segmented), P5, P6 and in genital segmentation; sometimes in $\mathrm{P} 2, \mathrm{P} 4$ or caudal rami.

Antennula short, with outer spinous process on segments I (prominent) and II (weakly developed); with numerous pinnate setae and spines; 4-segmented in female, with aesthetasc on segment III; 5-segmented and modified (segment IV extremely swollen, segments distal to geniculation fused) in male with geniculation between segments IV and V and with aesthetascs on segments IV and sometimes V. Antenna with allobasis; abexopodal seta and exopod absent; endopod with 6 distal elements and 2 lateral spines. Labrum undivided, with three sets of spinules. Mandible with bi-segmented uniramous palp; endopod represented by distal segment with 4 setae. Paragnaths well developed, strongly ornamented lobes. Maxillule with unisegmented, bisetose exopod; endopod incorporated into basis, with 3 setae; basal endites well defined, proximal one with 2 setae, distal one with 1 claw and 2 setae. Maxillary syncoxa with 3 (or 2) endites, precoxal endite (when present) vestigial, with 1 seta; middle endite with specialized spine; endopod incorporated into basis, with 2-3 setae. Maxilliped with syncoxa bearing 1 seta; basis asetose; endopod unisegmented with 2 setae and 1 long claw.

P1 with well developed 3-segmented protopod; precoxa (1) and coxa (2) with conspicuous crests along outer margin; basis with inner spine located on anterior surface near the inner margin, without real pedestal for insertion of endopod; exopod 3-segmented, distal segment with 4 geniculate setae; 
endopod prehensile, 2-segmented with elongated enp-1 (sometimes bearing inner seta) and short enp-2 with 1 short claw (plus 1 long, geniculate claw). P2-P4 with 3-segmented exopods and 1- or 2-segmented endopods; spine- and seta formulae as follows:

$\begin{array}{lll} & \text { Exopod }\left(^{*}\right) & \text { Endopod } \\ \text { P2 } & 0 .[0-1] .122 & 1.120 \\ & & \text { (or 220) } \\ \text { P3 } & 0 .[0-1] .222 & 22[0-1] \\ \text { P4 } & 0.0 .222 & 220\end{array}$

(* outer and outer apical spines of exp-3 are very elongated and resemble genuine setae in Cristacoxidae)

Female fifth pair of legs not fused medially, defined at the base, remnant of intercoxal sclerite present, no distinction between exopod and baseoendopod; with 8 setae. Position, segmentation and number of armature elements of male fifth pair of legs similar to female.

Female gonopores not fused medially and each covered laterally by vestigial P6 bearing 2 tiny setae and sometimes very long seta; copulatory pore large, located in median depression; seminal receptacles paired, well defined. One egg-sac.

Male P6 asymmetrical, with 2 setae each; either left or right P6 fused to ventral wall of supporting somite, other member articulating and closing off gonopore. Reproductive system asymmetrical with single functional gonopore releasing one spermatophore at a time. Spermatophore big, 1/3 of total body length, with long neck. Male grasping terminal setae of female's caudal rami during precopulatory phase.

Marine, interstitial, freeliving.

Type genus. - Cristacoxa gen. nov.

Other genera. - Noodtorthopsyllus Lang, 1965; Cubanocleta Petkovski, 1977.

\section{Genus Cristacoxa gen. nov.}

Diagnosis. - Cristacoxidae. Sexual dimorphism in antennula, P3 endopod, P4 endopod, P5, P6 and in genital segmentation. Seta $\mathrm{V}$ of caudal rami biarticulated; consisting of strong basal part and flagella-like apical part. Segment I of antennules without inner spinous process; outer process small. Maxilla with 2 setae on endopod; precoxal endite present, represented by 1 seta. P1 with moderately developed cristae on coxa; enp-1 without inner seta. P2 with 2-segmented endopod; with inner seta on exp-2; without sexual dimorphism. P3 with inner seta on exp-2; endopod without outer spine. Male endopod P3 2-segmented; enp-1 with long, sigmoid, inner apophysis (homologous with proximal inner seta of female) being 2.25 times the length of entire endopod; enp-2 with 1 long plumose seta (2 setae lost in comparison to the female). Male endopod P4 with 1 inner seta instead of 2. P5 of male with 2 setae and 6 spines. Genital complex of female unconfirmed.

Type species. - Cristacoxa petkovskii gen. et spec. nov.

Other species. - None.

Etymology. - The generic name is derived from the Latin crista, meaning crest, and coxa, meaning hip, and refers to the conspicuous outer crests found on the precoxa and coxa of the first leg.

Cristacoxa petkovskii gen. et spec. nov.

Material. - Amsterdam Expeditions to the West Indian Islands, Sta. 84-226. Bonaire, Lac, on shore near the hotel ruins of Sorobon; $12^{\circ} 05^{\prime} 53^{\prime \prime} \mathrm{N} 68^{\circ} 14^{\prime} 02^{\prime \prime} \mathrm{W}$; 11 June 1984; coll. J.H. Stock. One male (holotype, ZMA Co. 102.846) dissected and mounted on 10 slides.

Description. - Male (Figs. 1A-B; $2 \mathrm{H}-\mathrm{I} ; 3 \mathrm{~A}-\mathrm{D}$; $4 A-H)$. Total body length $480 \mu$ from the tip of the rostrum to the posterior margin of the caudal rami. Maximum width $105 \mu$ measured slightly anterior to the rear margin of the cephalothorax. Rostrum (Figs. 1A-B; 2A) with broad base, slightly deflexed, bell-shaped, ornamented with a pair of tiny setules subterminally and a midventral tubepore near the apex. Body (Figs. 1A-B) cylindrical, without deep constrictions between the somites, gradually tapering posteriorly; body somites and caudal rami covered with minute denticles (Fig. 3A); integument with numerous small, round, cuticular depressions arranged either in narrow bands both dorsally and laterally in the anterior half of 


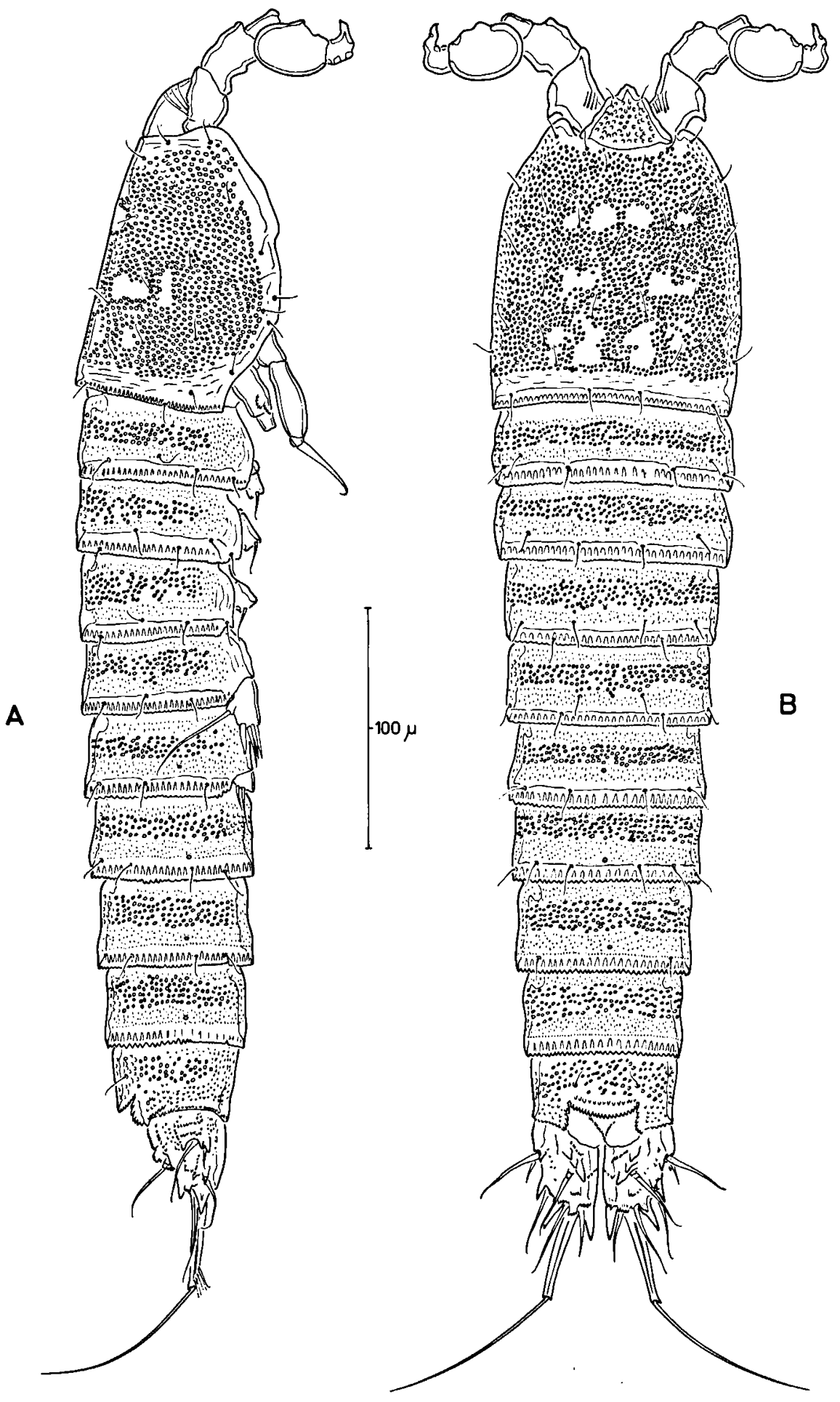

Fig. I. Cristacoxa petkovskii gen. et spec. nov. Male: A, habitus, lateral view; B, habitus, dorsal view. 

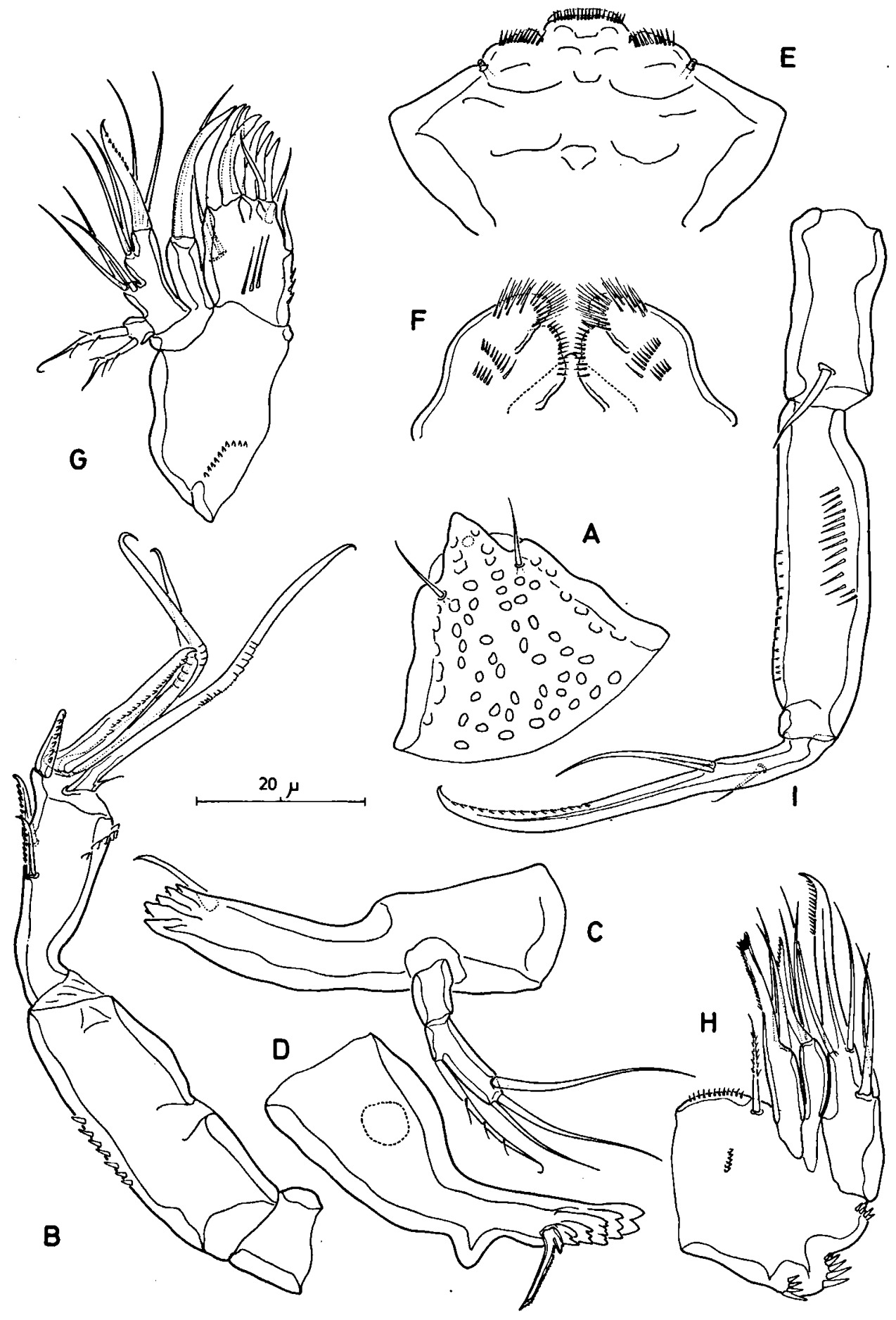

Fig. 2. Cristacoxa petkovskii gen. et spec. nov. Male: A, rostrum; B, antenna; C, mandible; D, mandible of other side (palp omitted); E, labrum; F, paragnaths; G, maxillula; H, maxilla; I, maxilliped. 
thoracic and abdominal somites, or in more or less symmetrical pattern distributed over the cephalic shield. Cephalothorax almost rectangular in dorsal view, moderately produced ventrally; posterior margin denticulate. Pleurotergites of thoracic somites also with denticulate hind margin; P5- and P6-bearing somites with few ventral ornamentation (Figs. 1A-B). Ventral and ventrolateral hind margins of abdominal somites finely denticulate; incisions deeper and coarser dorsally and dorsolaterally (Fig. 3A). Anal somite (Figs. 1A-B; 3A; 4D) with serrate, moderately developed operculum and two tiny sensillae dorsally; anal vestibulum pentagonal, lateral margins pectinate, hind margins formed by spinular row on caudal rami (Fig. 4D). Caudal rami (Figs. 3A; 4D-E) short, slightly longer than maximum width; tapering posteriorly; with 7 setae of which most are flanked by spinous processes: VII tri-articulated and covered at base; seta $\mathrm{V}$ strongly developed, consisting of basal styliform part which is plumose near the articulation with the flagellalike distal part.

Antennula (Figs. 4F-H) 5-segmented, modified, geniculation between segments IV and V; segment I with few long spinules and slightly backwardly directed, outer spinous process; segment II with weakly developed, outer spinous process; segment IV swollen and with complex ornamentation; segment $\mathrm{V}$ with backwardly directed apex. Setal ornamentation: I-1 pinnate; II- $[8+2$ pinnate]; III-10; IV-[10 +1 pinnate +4 modified + aesthetasc]; V-[9+ aesthetasc].

Antenna (Fig. 2B) with small, unornamented coxa; allobasis with minute spinules along inner margin; abexopodal seta and exopod absent; endopod with 2 curved spines laterally, with 2 spines and 3 geniculate setae distally (outermost geniculate seta bipinnate and fused with short seta).

Labrum (Fig. 2E) a simple muscular lobe with 2 pores and 3 patches of fine spinules medially.

Mandible (Figs. 2C-D) with well developed gnathobase bearing several multicuspidate teeth and a bifid, pinnate, recurved spine; palp uniramous: basis asetose, endopod with 1 pinnate and 3 smooth setae, exopod absent.

Paragnaths (Fig. 2F) well developed, bilobed, and heavily ornamented with fine spinules; with triangular process in between.
Maxillula (Fig. 2G) with well developed arthrite armed with 7 terminal spines/setae, 2 inner setae and 2 setae on posterior surface; coxa with 1 curved spine plus 1 seta on its endite; basis with two endites (proximal with 2 setae; distal with 2 setae and 1 claw); endopod represented by 3 setae; exopod unisegmented, with 2 pinnate setae.

Maxilla (Fig. 2H) with 3 endites on syncoxa; proximal (precoxal) endite vestigial, with 1 seta, coxal endites with 2 setae and 1 pinnate claw each (claw of middle endite with complex apex and fused at the base); basis produced into a claw-like endite with 2 setae; endopod incorporated into basis, with 2 setae.

Maxilliped (Fig. 2I) with 1 smooth seta on syncoxa; basis asetose, with 2 spinular rows; endopod represented by long, distally denticulate claw bearing 2 setae.

Thoracopods with wide intercoxal sclerites and well developed precoxae. Leg 1 (Fig. 3B) with large precoxa, with short spinules anteriorly and deeply incised crest at outer margin; coxa with several patches of spinules anteriorly and 2 moderately developed, serrate crests at outer margin; basis with pinnate spine on anterior surface near inner margin and with smooth seta at outer margin; exp$1,-2$ with spinulose outer margin and 1 unipinnate spine or seta, exp-3 with 4 geniculate setae increasing in length adaxially; endopod 1.34 times as long as exopod, enp-1 longest, without inner seta but with spinules near outer margin, enp-2 with 1 short, denticulate claw and 1 long, geniculate claw.

P2-P4 (Figs. 3C; 4A-C). Coxa with outer, serrate crest (P2-P3) and/or with spinular rows; basis with smooth seta. Seta and spine formulae as follows:

$\begin{array}{lll} & \text { Exopod } & \text { Endopod } \\ \text { P2 } & 0.1 .122 & 1.120 \\ \text { P3 } & 0.1 .222 & \text { modified } \\ \text { P4 } & 0.0 .222 & \text { modified }\end{array}$

Endopod of P3 (Fig. 4A) 2-segmented; enp-1 with long sigmoid apophysis, arising from the inner margin and 2.25 times as long as entire endopod, apex slightly recurved (homologous with inner seta on enp-1 of female); enp-2 with long plumose seta 


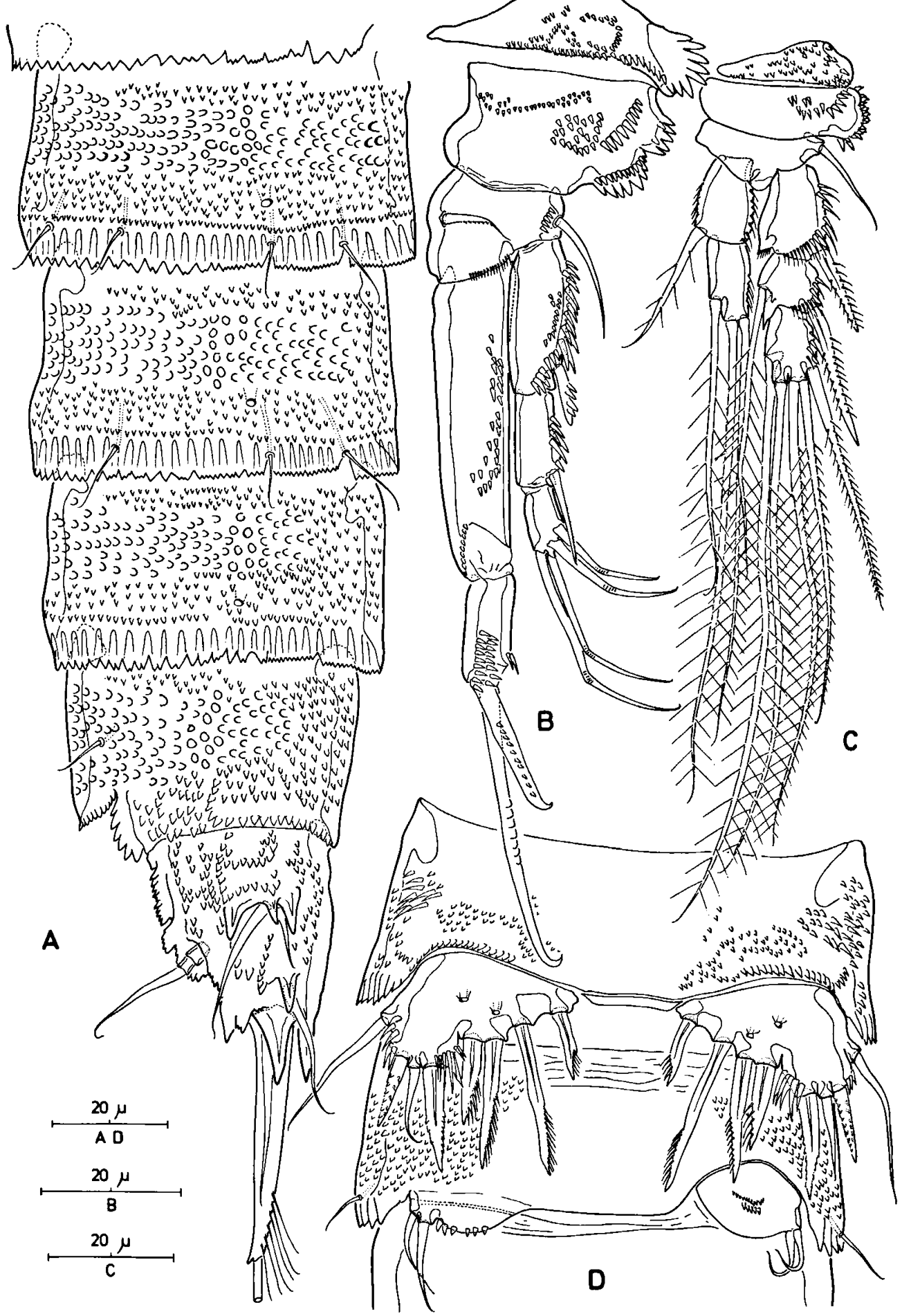

Fig. 3. Cristacoxa petkovskii gen. et spec. nov. Male: A, abdominal somites and caudal rami, lateral view; B, P1, anterior view; C, $\mathrm{P} 2$, anterior view; $\mathrm{D}$, fifth and sixth pairs of legs. 


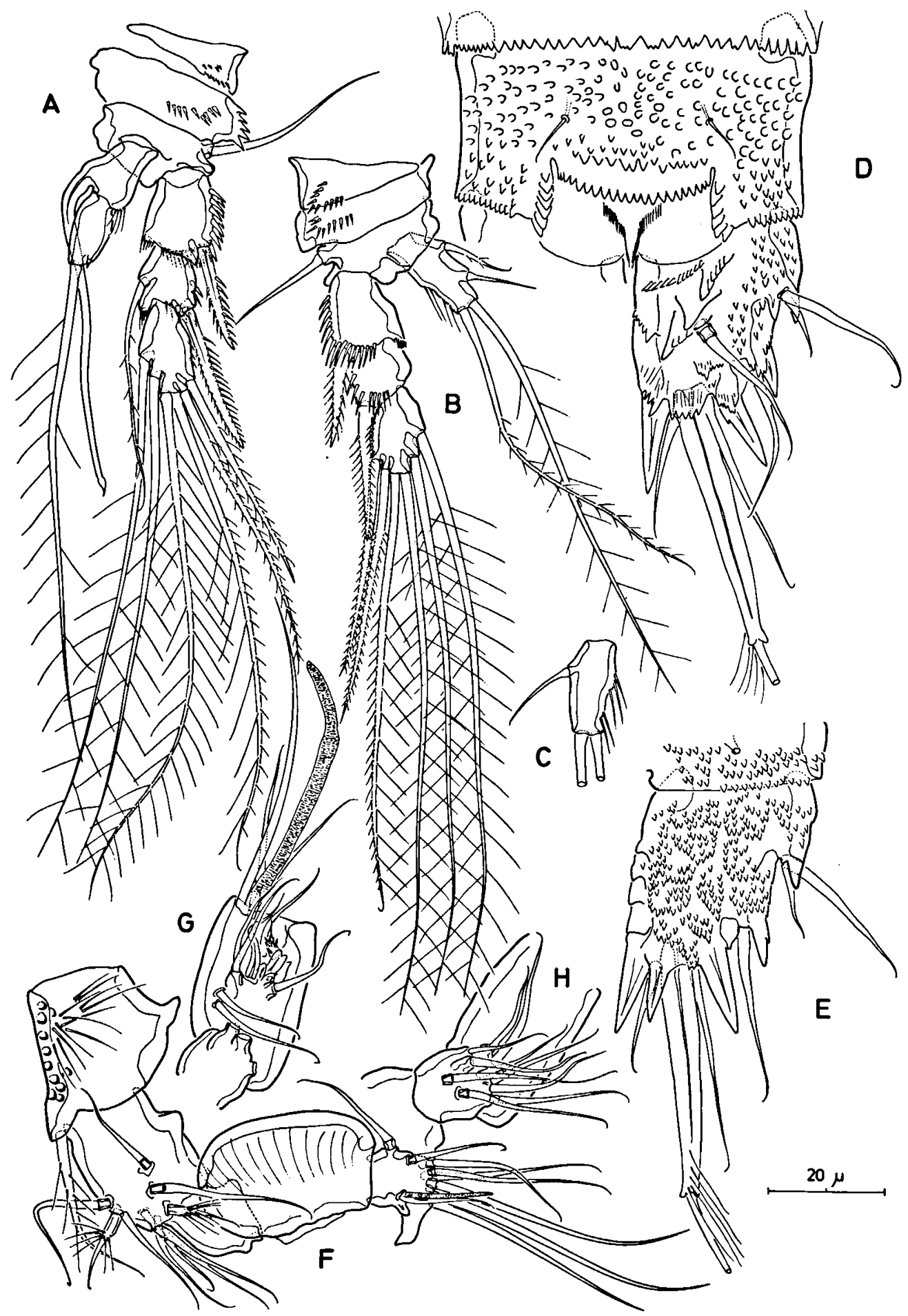

Fig. 4. Cristacoxa petkovskii gen. et spec. nov. Male: A, P3; B, right P4 (with 2 inner setae on endopod = atypical condition?); C, endopod of left P4 (typical condition ?); D, anal somite and right caudal ramus, dorsal view; E, left caudal ramus, ventral view; F, antennula (ornamentation of segments II and IV omitted); G, antennula, inner lateral view of segment IV; H, antennula, inner lateral view of segment III. 
apically and 1 minute spinous process representing vestigial seta.

Endopod of P4 (Fig. 4C) 1-segmented; with 2 long apical setae and 1 inner seta in the typical condition; right endopod (Fig. 4B) aberrant, with 2 inner setae (see sexual dimorphism in Cubanocleta).

Fifth pair of legs (Fig. 3D) not fused to supporting somite, rami fused but without real distinction between endopodal and exopodal lobes, with remnant of intercoxal sclerite. Armature consisting of 6 pinnate spines and 2 naked setae; 2 secretory pores discernible on anterior surface.

Sixth pair of legs (Fig. 3D) asymmetrical; represented on both sides by a small plate (fused to ventral wall of supporting somite along one side; articulating at base and covering gonopore along the other side) with 2 short setae at the outer corner. Only one gonopore is functional (the right one in Fig. 3D). One very large but slender spermatophore with long, curved neck.

Female. Unknown.

Etymology. - The species is dedicated to Dr. Trajan K. Petkovski, Prirodonaucen Muzej, Skopje, in appreciation of his valuable contributions to copepod taxonomy.

Remarks. - The new genus Cristacoxa is closely related to Noodtorthopsyllus. They share the same type of sexual dimorphism on the endopod of P3, the bi-articulated seta $\mathrm{V}$ on the caudal rami, the segmentation and ornamentation of the endopods of P2-P4 and the gross morphology of leg 5. The new genus however lacks the inner seta on enp-1 of the P1, a characer displayed only by $N$. psammophilus. On the other hand it is the only genus that has retained the precoxal endite of the maxilla. Noodtorthopsyllus exhibits sexual dimorphism on the endopod of leg 2, i.e. the males lack the inner seta of the proximal endopod segment. The description of $C$. petkovskii is based on a single male specimen, but the presence of the latter seta on the same limb indicates that the genus Cristacoxa shows no sexual dimorphism on the P2 endopod. Conversely, $N$. psammophilus displays no sexual dimorphism on leg 4 whereas the male of $C$. petkovskii shows only 1 inner seta (i.e. the proximal one) opposed to the probable number of 2 found in the female (and shown by the aberrant condition in one of the endopods: Fig. 4B). It is interesting to note that the latter modification on leg 4 is also found in the genus Cubanocleta. Other useful characters to distinguish Cristacoxa and Noodtorthopsyllus are the length of the male apophysis of the P3 endopod and the shape of the coxal outer crests on leg 1 . Since both generic names Noodtorthopsyllus and Cubanocleta refer to genera that bear no direct relationships with Cristacoxa, it is preferred to chose the latter as type genus of the family because it refers to one of the most distinctive features of the family, the presence of crests ("cristae") on the precoxa and coxa of leg 1 (and sometimes P2 and P3).

\section{Genus Noodtorthopsyllus Lang, 1965}

Orthopsyllus Brady \& Robertson, 1873 (part.)

Diagnosis. - Cristacoxidae. Sexual dimorphism in antennula, P2 endopod, P3 endopod, P5, P6 and in genital segmentation (and caudal rami?). Seta $V$ of caudal rami bi-articulated; consisting of strong basal part and flagella-like apical part. Segment I of antennules without inner spinous process; outer process small. Maxilla with 3 setae on endopod; precoxal endite absent. P1 with strongly developed cristae on coxa; enp-1 with inner seta. P2 with 2-segmented endopod; with inner seta on exp-2; with sexual dimorphism (loss inner seta of enp-1; inner distal seta of enp-2 shorter). P3 with inner seta on exp-2; endopod without outer spine. Male endopod P3 indistinctly 2-segmented; enp-1 with long, sigmoid, inner apophysis (homologous with proximal inner seta of female) being 1.25 times the length of entire endopod; enp-2 with 1 long plumose seta ( 2 setae lost in comparison to the female). P5 of female not bilobate. P5 of male with 2 setae and 6 spines. Genital complex of female with P6 represented by 1 long pinnate seta and 2 vestigial setules.

Type species. - Noodtorthopsyllus psammophilus (Noodt, 1955) 
Other species. - None.

Noodtorthopsyllus psammophilus (Noodt, 1955)

Orthopsyllus psammophilus Noodt, 1955:208-212, Figs. 9-23; 1958: 81

Material examined. - Amsterdam Expeditions to the Canary Islands. (1) Sta. 87-32; Tenerife, Pozo Playa, San Marcos; conductivity $1914 \mu \mathrm{s} / \mathrm{cm} ; 24$ April 1987; coll. J.H. Stock \& E. Sánchez: 1 male (retained in personal collection of author); (2) Sta. 87-39; El Hierro, Pozo La Bonanza; conductivity $6.86 \mathrm{~ms} / \mathrm{cm}$; 27 April 1987; coll. J.H. Stock: 1 female (retained in personal collection of author).

Redescription. - Only a brief redescription is given with emphasis mostly placed on the limbs or structures that show sexual dimorphism.

Female (Figs. 5A, D; 6A, B, D; 7A, C, E)

Antennula (Fig. 5A) 4-segmented, very short. Segment I with 2 patches of fine spinules and spinous, outer process; segment II with minute spinous, outer process; segment III longest; segment IV with 2 basally fused setae. Setal ornamentation: I-1 pinnate; II-[7 +2 pinnate]; III- $[9+1$ pinnate + aesthetasc]; IV-[8 +3 pinnate + aesthetasc].

Maxilliped (Fig. 6B) with 1 pinnate seta on syncoxa; basis asetose, with denticulate inner margin; endopod represented by minute segment with long, distally serrate claw bearing 2 setae.

P1 (Fig. 6A) with large precoxa, with deeply incised crest at outer margin; coxa with several patches of spinules anteriorly and 2 rounded, strongly developed, double serrate crests at outer margin; basis with pinnate spine on anterior surface near inner margin and with smooth seta at outer margin; exp-1, -2 with spinulose outer margin and 1 pectinate spine (exp-1) or unipinnate seta (exp-2), exp-3 with 4 geniculate setae increasing in length adaxially; endopod 1.29 times as long as exopod, enp-1 long, with tiny plumose seta and some spinules along the inner margin, enp-2 with 1 short, denticulate claw and 1 long, geniculate claw.

P2-P4 (Figs. 7C, E) with following seta and spine formula:

$\begin{array}{lll} & \text { Exopod } & \text { Endopod } \\ \text { P2 } & 0.1 .122 & 1.120 \\ \text { P3 } & 0.1 .222 & 220 \\ \text { P4 } & 0.0 .222 & 220\end{array}$

P5 (Fig. 6D) represented by a single plate separated from the other member by a minute intercoxal sclerite. Anterior surface with 3 secretory pores and densely covered with fine denticles. Armature consisting of 2 bare spines, 2 long pinnate spines, 2 short pinnate spines and 2 bare setae.

Genital complex (Fig. 5D) with large copulatory pore flanked by 2 secretory pores; P6 represented by small protuberance bearing long pinnate seta and 2 vestigial setules.

Caudal ramus (Fig. 7A) short; tapering posteriorly; covered with numerous minute spinules; with 7 setae of which most are flanked by spinous processes; setae IV and V with common base; seta $\mathrm{V}$ strongly developed, consisting of basal, denticulate, styliform part which is plumose near the articulation with the flagella-like distal part.

Male (Figs. 5B-C; 6C; 7B, D, F, G)

Antennula (Figs. 5B-C) 5-segmented, modified, geniculation between segments IV and V; segment I with weakly developed, outer process; segment II also with weakly developed, blunt, outer process; segment IV swollen and with complex ornamentation; segment $V$ with backwardly directed apex and 2 basally fused setae. Apex of segment $V$ touching modified spine of segment IV during clasping (Fig. 5C). Setal ornamentation: I-1 pinnate; II- $[8+2$ pinnate]; III-9; IV-[9 +2 pinnate +2 modified + aesthetasc]; V-[11 + aesthetasc].

Endopod P2 (Fig. 7D) 2-segmented; enp-1 shorter than in female and missing inner seta and spinules; enp-2 slightly longer, with inner apical seta shorter than in female.

Endopod P3 (Figs. 7F-G) indistinctly 2-segmented; inner margin of enp-1 with long sigmoid apophysis, being 1.25 times the length of total endopod and slightly swollen at the tip (homologous with proximal inner seta of female); enp-2 with 1 long, plumose seta distally and two minute, spinous processes (representing vestigial setae). 


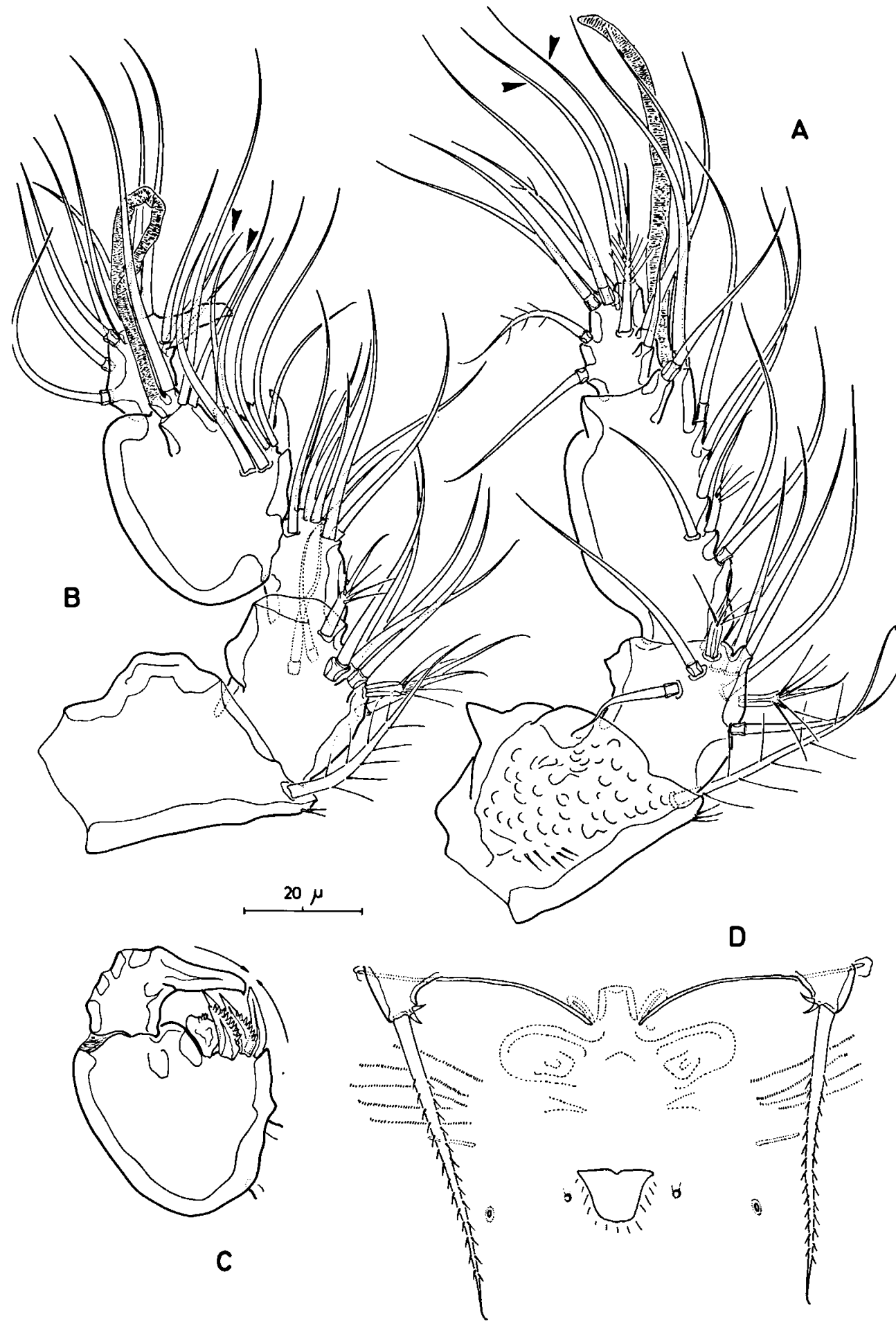

Fig. 5. Noodtorthopsyllus psammophilus (Noodt, 1955). Female: A, antennula (arrows indicating basally fused setae); D, genital complex. Male: B, antennula (arrows indicating basally fused setae; modified spines on segment IV omitted); C, antennule, distal segments (showing modified spines on segment IV). 


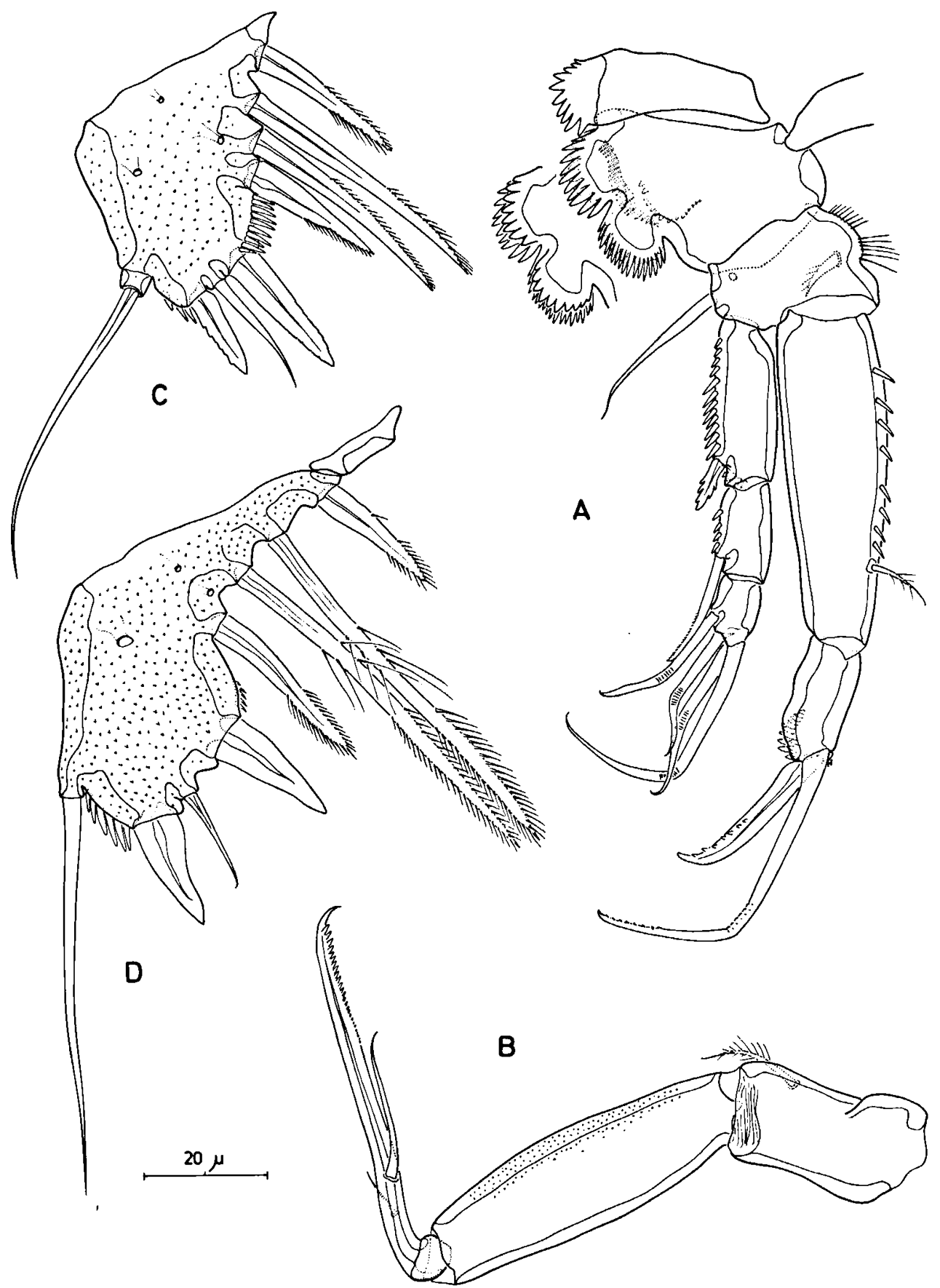

Fig. 6. Noodtorthopsyllus psammophilus (Noodt, 1955). Female: A, P1, posterior view (with anterior view of coxal cristae); B, maxil liped; D, P5. Male: C, P5.

P5 (Fig. 6C) represented by a single plate not fused to the supporting somite; anterior surface covered with numerous minute denticles and 3 secretory pores; armature consisting of 2 long unipinnate spines, 2 short pinnate spines, 2 weakly serrate spines, and 2 bare setae. 


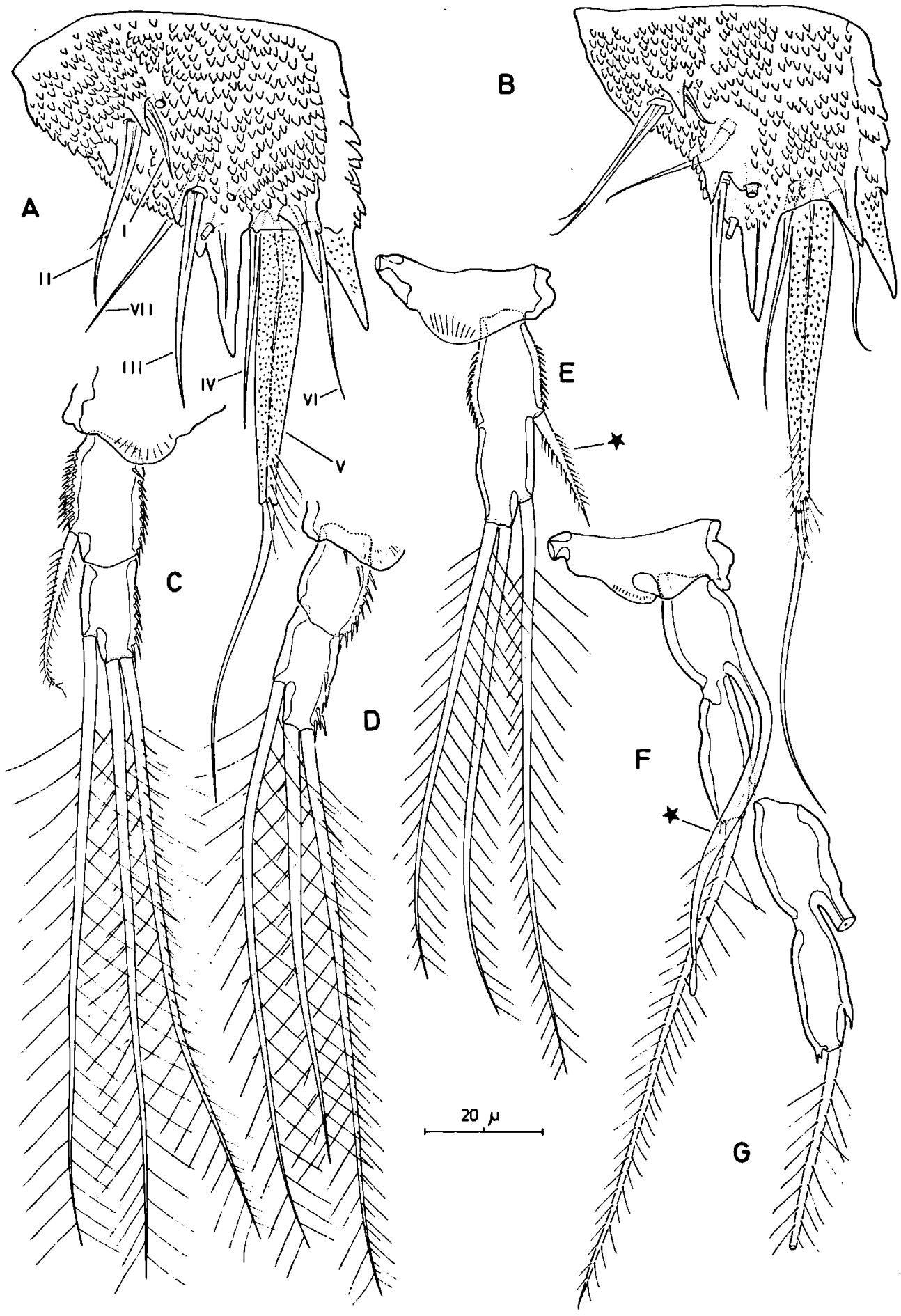

Fig. 7. Noodtorthopsyllus psammophilus (Noodt, 1955). Female: A, right caudal ramus, ventral view; C, endopod of P2; E, endopod of P3. Male: B, right caudal ramus, ventral view; D, endopod of P2; F, endopod of P3; G, same, apophysis omitted. Asterisks indicating homologous structures. 
Sixth pair of legs asymmetrical; represented on both sides by a small plate (fused to ventral wall of supporting somite along one side; articulating at base and covering gonopore along the other side) with 2 setae at the outer corner. One very large but slender spermatophore with long, curved neck.

Remarks. - The original description by Noodt (1955) is fairly detailed, but contains some inaccuracies. For instance, Noodt has transposed the drawings of P2 and P4 (Abb. 11 \& 14: 209) although he presents the correct setal formula in the text. The sexual dimorphism on the endopod of P2 was overlooked. The presumed slight sexual dimorphism on the caudal rami is a character difficult to quantify. The present redescription revealed only some minute differences (cf. comparison of Figs. $7 \mathrm{~A}-\mathrm{B}$ ) but these can hardly be attributed to sexual dimorphism.

\section{Genus Cubanocleta Petkovski, 1977}

Diagnosis. - Cristacoxidae. Sexual dimorphism in antennula, P2 endopod, P3 endopod, P4 (both rami), P5, P6 and in genital segmentation. Seta V of caudal rami simple. Segment I of antennules with inner spinous process; outer process long. Maxilla with 3 setae on endopod; precoxal endite absent. P1 with strongly developed cristae on coxa; enp-1 without inner seta. P2 with 1-segmented endopod; without inner seta on exp-2; with sexual dimorphism (outer apical seta pinnate in distal half; distal inner seta longer). P3 without inner seta on exp-2; endopod with outer spine. Male endopod P3 1-segmented; with short, slightly curved outer apophysis (homologous with outer spine of female) and 2 setae ( 2 setae lost in comparison to the female); inner apophysis absent. Male P4 with exp-2, -3 shorter than in female; endopod short, with 1 seta and 1 setule at inner margin. P5 of female bilobate. P5 of male with 7 setae and 1 spine. Genital complex of female with P6 represented by 2 vestigial setules only.

\section{Type species. - Cubanocleta noodti Petkovski,} 1977

Other species. - None.

\section{Cubanocleta noodti Petkovski, 1977}

Cubanocleta noodti Petkovski, 1977: 57-68, Figs. 1-23

Material examined. -

(1) Amsterdam Expeditions to the West Indian Islands, Sta. 84-139; Curaçao, Kennedy Boulevard, $500 \mathrm{~m}$ east of Concorde Hotel; $12^{\circ} 07^{\prime} 13^{\prime \prime}$ N 68 $67^{\circ}$ 50"W; 1 June 1984; coll. J.H. Stock \& J.J. Vermeulen: 2 males (ZMA Co.102.847) preserved in alcohol.

(2) Amsterdam Expeditions to the West Indian Islands, Sta. 84-73; Klein Curaçao, east coast, exposed coralline sand; 19 May 1984; coll. J.H. Stock \& J.J. Vermeulen: 1 male preserved in alcohol (retained in personal collection of author).

(3) Amsterdam Expeditions to the West Indian Islands, Sta. 88-100; Bonaire, Piedra Haltu (1000-Step Beach), coarse coralline sand at tidal level; 4 June 1988; coll. J.H. Stock: 1 male dissected and mounted on 7 slides (retained in personal collection of author).

(4) From Prof. Dr. A. Coomans: 1 male (alcohol preserved) and 1 female (dissected and mounted on 10 slides) collected in front of marine laboratory in Bahía Academy, Isla Santa Cruz, Galápagos; 18 February 1988; coll. A. Coomans (retained in personal collection of author).

(5) From Dr. T.K. Petkovski: 2 males from type-locality; Second Cuban-Romanian Biospeleological Expedition to Cuba, Sta. 61; mouth of Rio Baconao, east of Santiago de Cuba near Gran Piedra, Oriente; collected with Karaman-Chappuis method in coarse sand situated $50 \mathrm{~m}$ from sea; influenced by fresh water; temperature $27.5^{\circ} \mathrm{C}$; 24 March 1973; coll. L. Botosaneanu \& J. Marrero. Accompanying copepod fauna: Schizopera tobae cubana Petkovski and Nitocra lacustris sinoi Marcus \& Por.

Redescription. - Female (Figs. 8A-B; 9A-E; $10 \mathrm{E}-\mathrm{F} ; 11 \mathrm{~A}-\mathrm{C} ; 12 \mathrm{~B}-\mathrm{E} ; 13 \mathrm{~A}-\mathrm{B}, \mathrm{D})$. Total body length $610 \mu$ from the tip of the rostrum to the posterior margin of the caudal rami. Maximum width $122 \mu$ measured at the rear margin of the cephalothorax. Rostrum (Figs. 8A-B; 9A) with broad base, slightly deflexed, bell-shaped; ornamented with a pair of tiny setules subterminally and a midventral tube-pore near the apex; dorsal surface with cuticular depressions. Body (Figs. 8A-B) cylindrical, without deep constrictions between the somites, gradually tapering posteriorly; body somites and caudal rami covered with minute denticles (Fig. 12C). Cephalothorax tapering anteriorly towards the rostrum; moderately produced ventrally; posteriolateral angles produced into rounded process; with numerous integumental pits varying in size and arranged in more or less sym- 

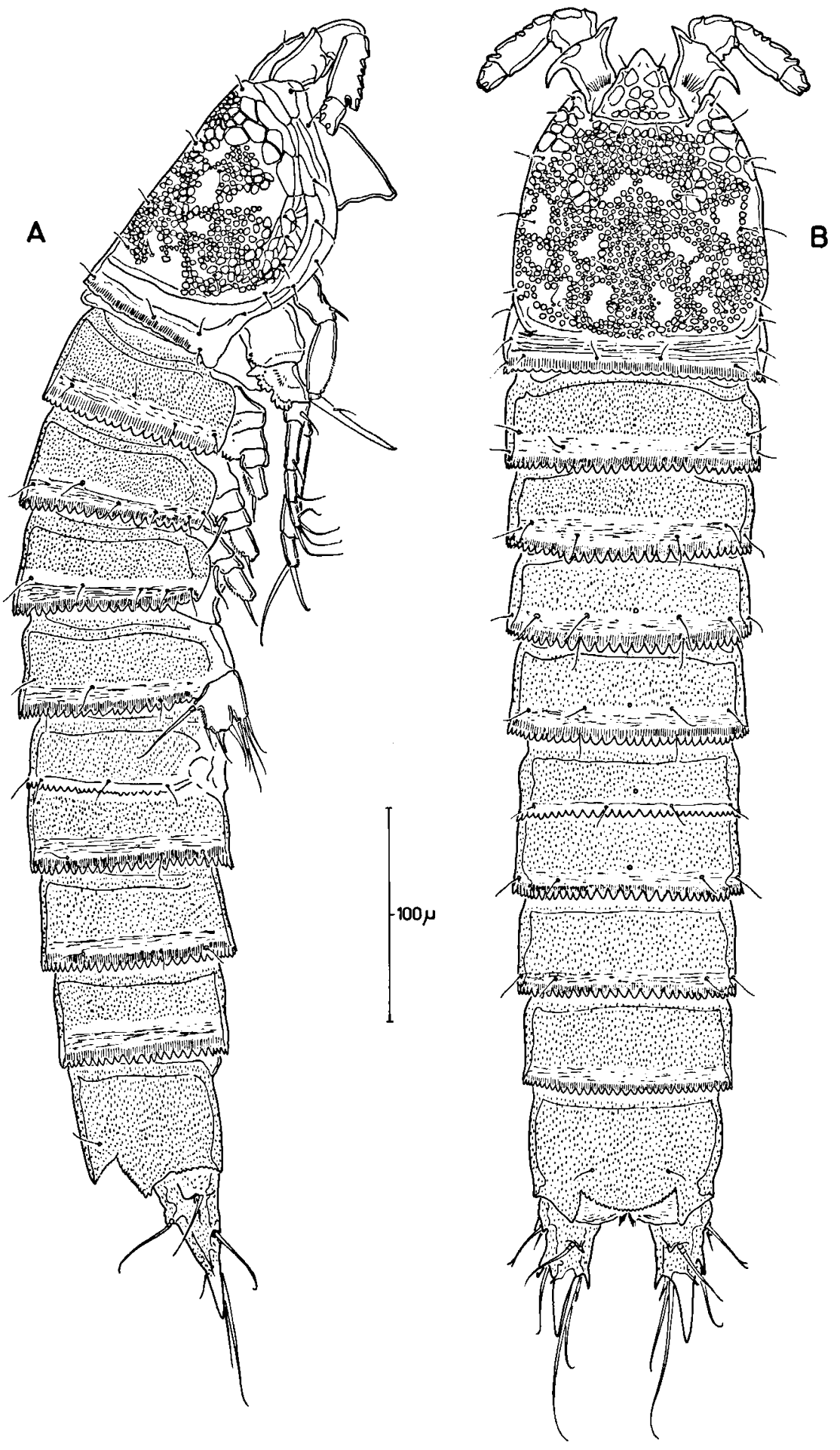

Fig. 8. Cubanocleta noodti Petkovski, 1977. Female: A, habitus, lateral view; B, habitus, dorsal view. 


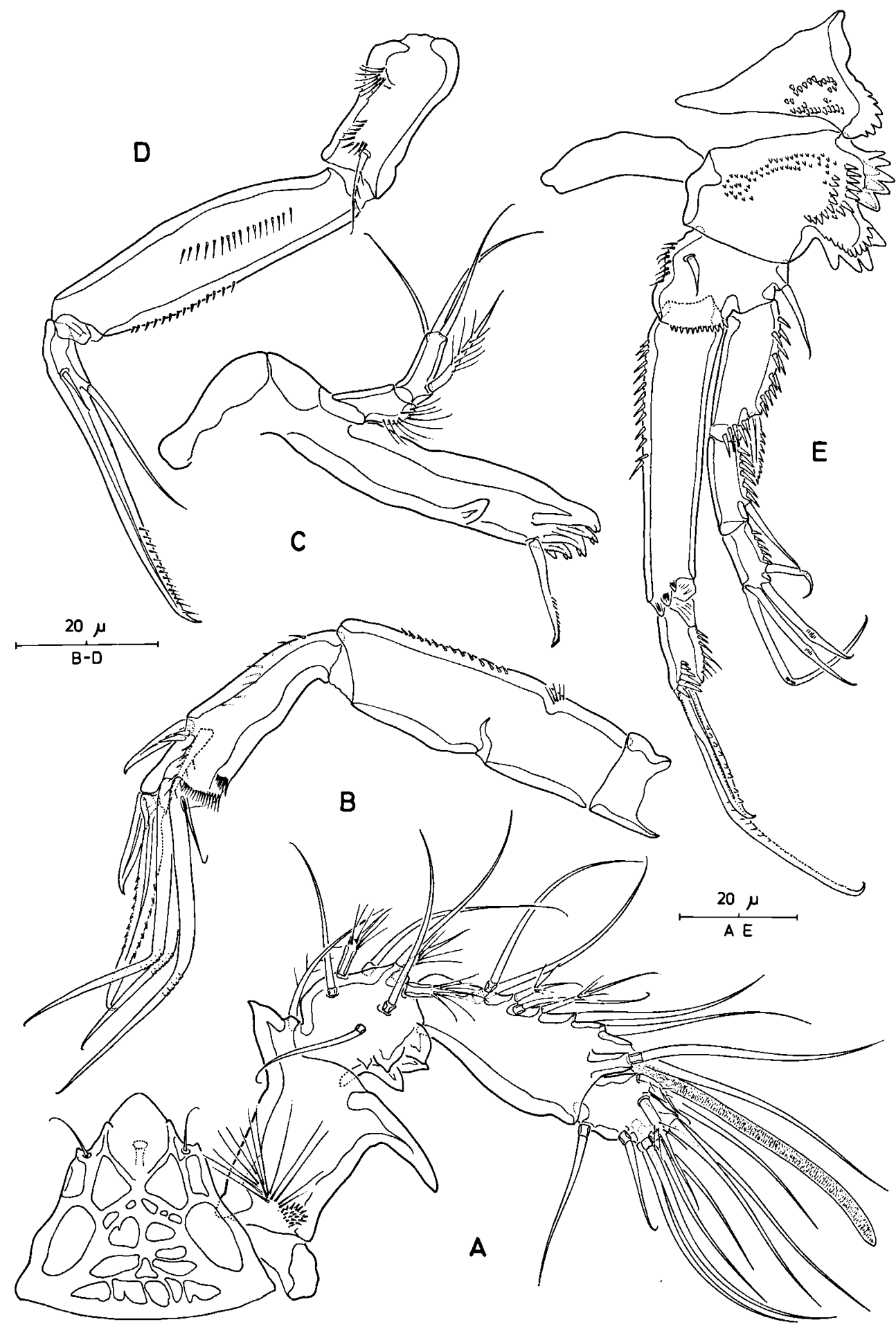

Fig. 9. Cubanocleta noodti Petkovski, 1977. Female: A, rostrum and antennula; B, antenna; C, mandible; D, maxilliped; E, P1, anterior view. 


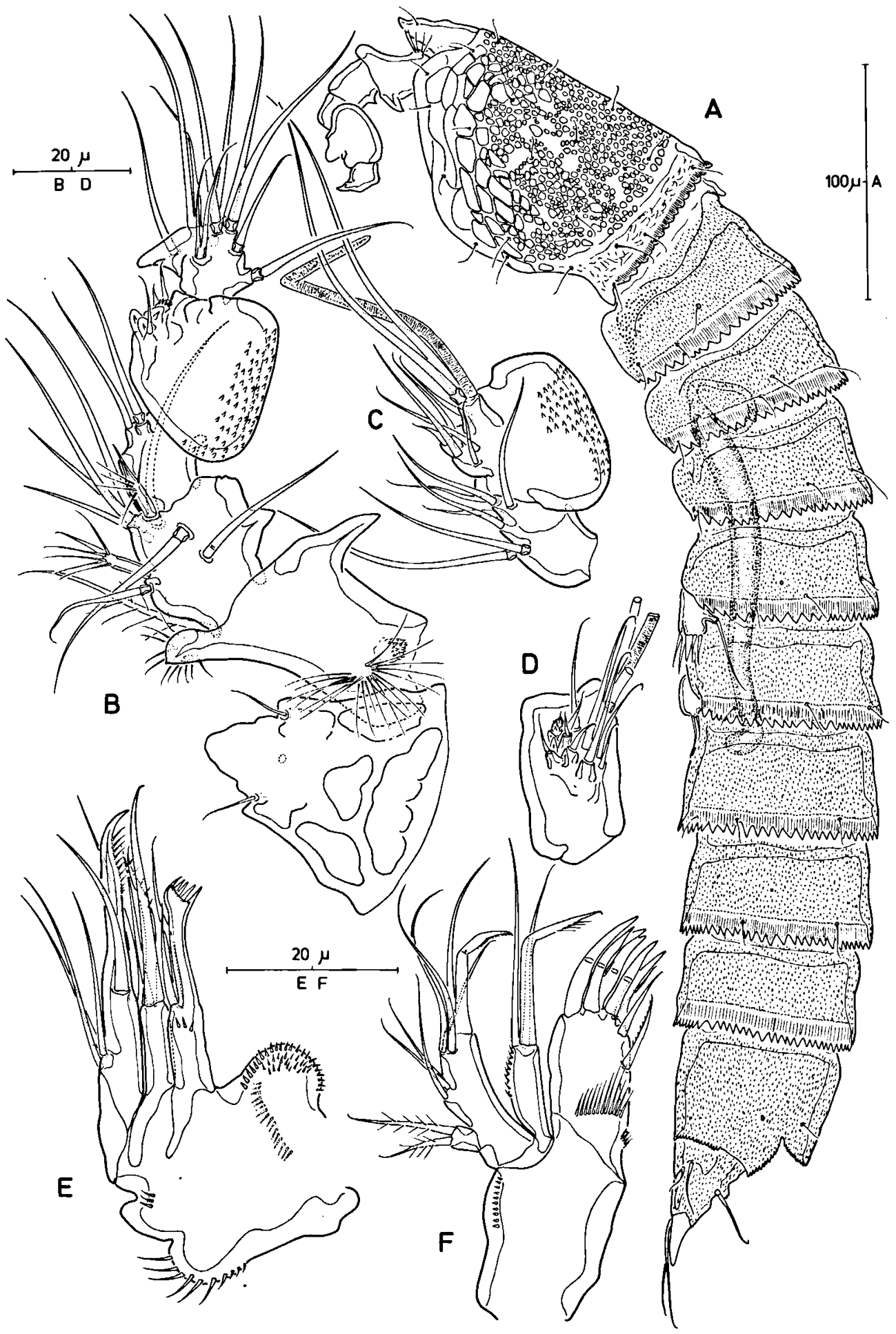

Fig. 10. Cubanocleta noodti Petkovski, 1977. Male: A, habitus, lateral view; B, rostrum and antennula (ventrolateral ornamentation of segments III and IV omitted; see C); C, antennula, segments III and IV showing ornamentation not drawn in B; D, antennula, inner lateral view of segment IV showing complete ornamentation. Female: E, maxilla; F, maxillula. 
metrical pattern. Hyaline frill of cephalothorax and all body somites striated and semi-incised obtusidigitate. Anal somite (Figs. 8A-B; 12C) with rounded, serrate, moderately developed operculum and two tiny sensillae dorsally; anal vestibulum broad, lateral margins pectinate, hind margins formed by spinular row on caudal rami (Fig. 12C). Caudal rami (Figs. 12C-D) short, produced posteriorly into terminal spinous process; slightly longer than maximum width and tapering posteriorly; covered with numerous minute spinules; with 7 setae of which most are flanked by spinous processes: VII tri-articulated and covered at base; seta $\mathrm{V}$ longest, simple.

Antennula (Fig. 9A) 4-segmented. Segment I with long outer and short inner spinous process, and 2 patches of spinules; segment II with multicuspidate outer process; segment III longest. Setal ornamentation: I-1 pinnate; II-[5 +3 pinnate]; III$[7+2$ pinnate + aesthetasc]; IV $-[9+2$ pinnate $]$.

Antenna (Fig. 9B) with small, unornamented coxa; allobasis with minute spinules along inner margin; abexopodal seta and exopod absent; endopod with 2 curved spines laterally, with 2 spines and 3 geniculate setae distally (outermost geniculate seta bipinnate and fused with short seta).

Labrum (Figs. 8A, 13B) a simple muscular lobe; strongly produced ventrally; with 3 patches of fine spinules medially; anterior face with epicuticular striations; pores not observed.

Mandible (Fig. 9C) with well developed gnathobase bearing several multicuspidate teeth and a unipinnate spine; palp uniramous: basis asetose but with long spinules, endopod with 1 pinnate and 3 smooth setae, exopod absent.

Paragnaths (Fig. 13A) well developed, with rich ornamentation consisting of fine spinular rows; without distinct process in between.

Maxillula (Fig. 10F) with well developed arthrite armed with 7 terminal spine/setae and 2 inner setae, setae on posterior surface absent; coxa with 1 curved spine plus 2 setae on its endite; basis with two endites (proximal with 2 setae; distal with 2 setae and 1 claw); endopod represented by 3 setae; exopod unisegmented, with 2 pinnate setae.

Maxilla (Fig. 10E) with 2 endites and a spinulose lobe on syncoxa; precoxal endite absent, coxal endites with 2 setae and 1 pinnate claw each (claw of proximal endite with complex apex and fused at the base); basis produced into a claw-like endite with 2 setae; endopod incorporated into basis, with 3 setae.

Maxilliped (Fig. 9D) with 1 pinnate seta and 2 spinular rows on syncoxa; basis asetose, with 2 spinular rows; endopod represented by long, distally pinnate claw bearing 2 setae.

Thoracopods with wide intercoxal sclerites and well developed precoxae. Leg 1 (Fig. 9E) with large precoxa, with short spinules anteriorly and semiincised crest at outer margin; coxa with several patches of spinules anteriorly and 2 strongly developed, double serrate crests at outer margin; basis with short bare spine on anterior surface near inner margin and with smooth seta at outer margin; exp-1, -2 with spinulose outer margin and 1 unipinnate spine or smooth seta, exp-3 with 4 geniculate setae increasing in length adaxially; endopod 1.4 times as long as exopod, enp-1 longest, without inner seta but with spinules along proximal inner margin, enp-2 with 1 short, denticulate claw and 1 long, geniculate claw.

P2-P4 (Figs. 11A-C). Coxae without outer, serrate crest, but with minute spinules; basis with smooth seta; all endopods 1-segmented. Seta and spine formulae as follows:

$\begin{array}{lll} & \text { Exopod } & \text { Endopod }\left(^{*}\right) \\ \text { P2 } & 0.0 .122 & 220 \\ \text { P3 } & 0.0 .222 & 221 \\ \text { P4 } & 0.0 .222\left({ }^{* *}\right) & 220\end{array}$

(*) The inner apical seta stands on a minute protuberance which places the outer apical seta in a relatively more external position (implying a 211 formula instead of 220); the latter seta is however homologous with the outer apical seta found in the other genera and in other families of the Laophontoidea and is not a genuine outer seta/spine as found on the P3 endopod. $\left({ }^{* *}\right)$ The outer and outer apical spines of P4 exp-3 are typically swollen at their bases.

P5 (Fig. 13D) represented by a single, bilobate plate separated from the other member by a minute intercoxal sclerite. Outer lobe with 1 long and 2 short, smooth setae and 1 peculiar, irregular spine furnished with strips of hyaline membrane; inner lobe with 4 spines/setae in total.

Genital complex (Figs. 12B, E) with moderately sized copulatory pore located in shallow depres- 


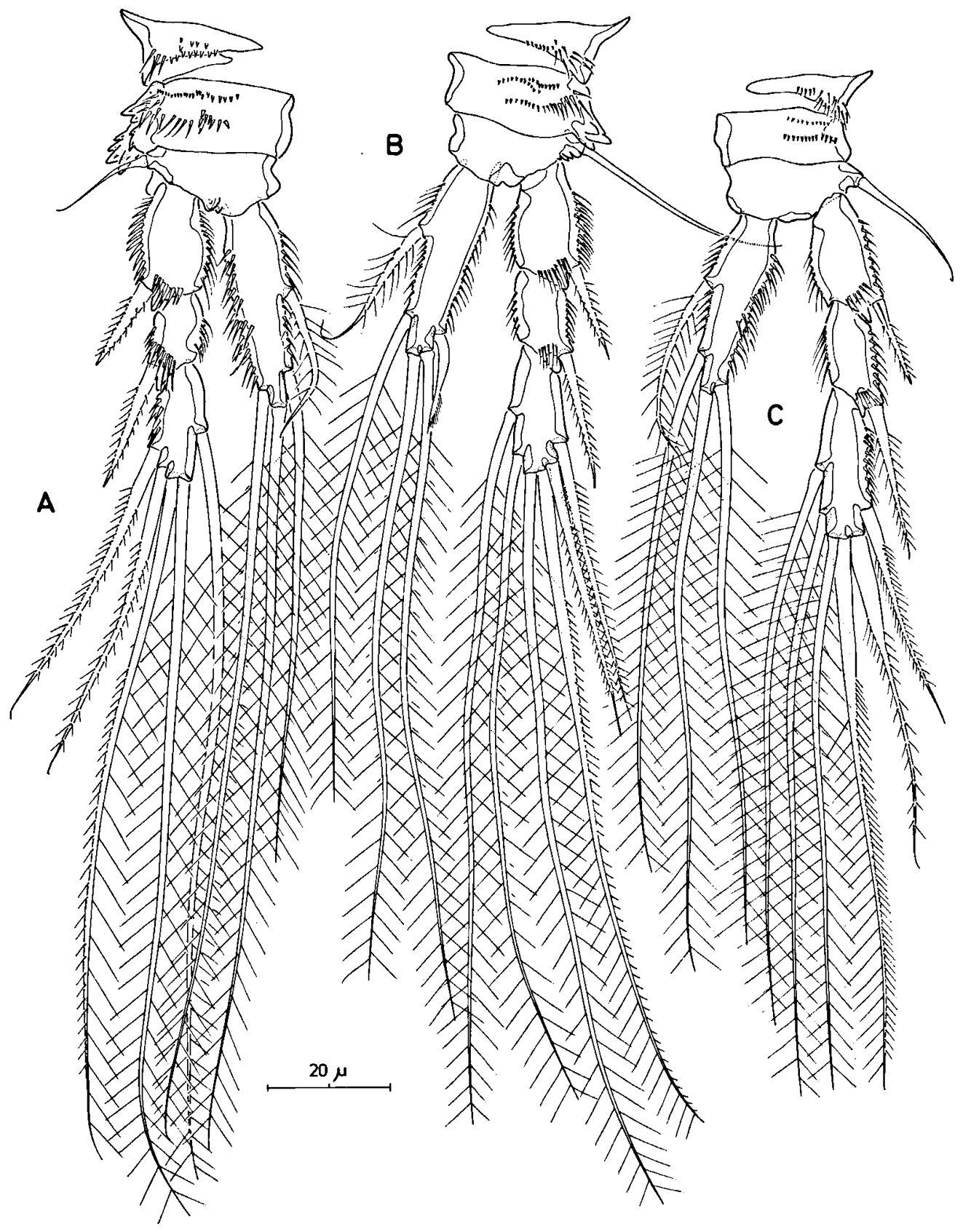

Fig. 11. Cubanocleta noodti Petkovski, 1977. Female: A, P2; B, P3; C, P4.

sion; P6 represented by 2 diminutive setules on either side.

Male (Figs. 10A-D; 12A; 13C, E-G).

Ornamentation of cephalothorax and body so- mites comparable to that of the female; genital and first abdominal somites fully separate (Fig. 10A); total body length $600 \mu$ measured from anterior tip of rostrum to hind margin of caudal rami.

Antennula (Figs. 10B-D) 5-segmented, modified, geniculation between segments IV and V; 


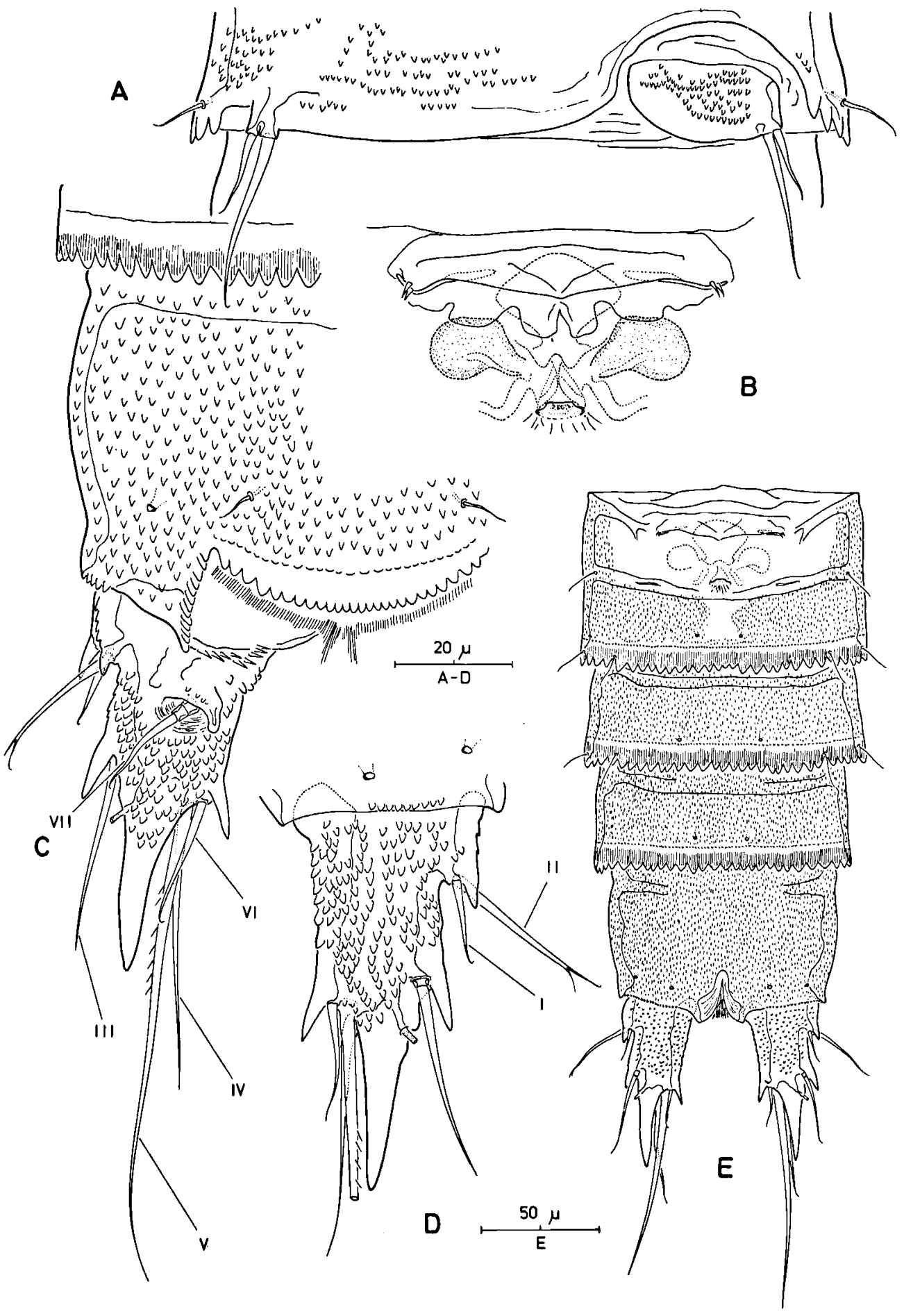

Fig. 12. Cubanocleta noodti Petkovski, 1977. Male: A, sixth pair of legs. Female: B, genital complex; C, anal somite and left caudal ramus, dorsal view; D, left caudal ramus, ventral view; E, urosome (exclusing P5-bearing somite), ventral view. 

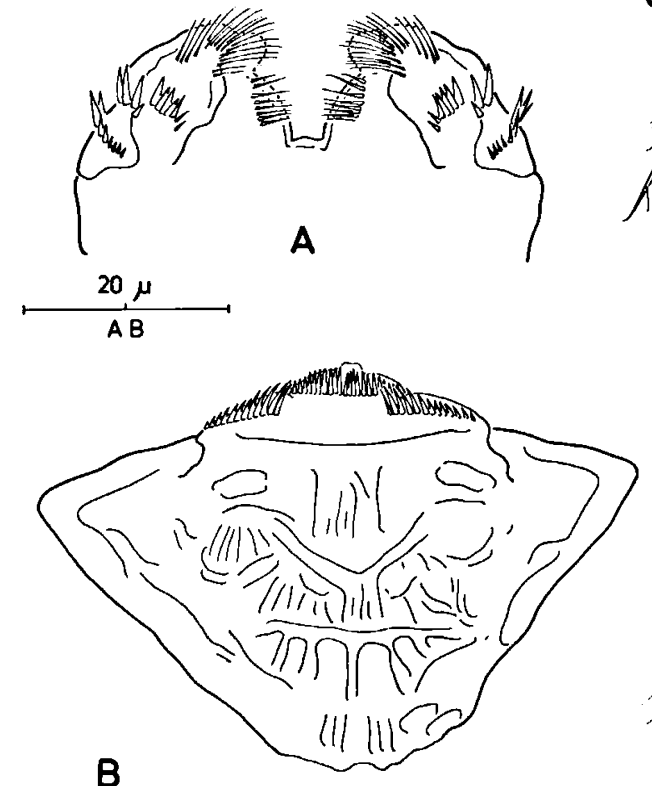

B
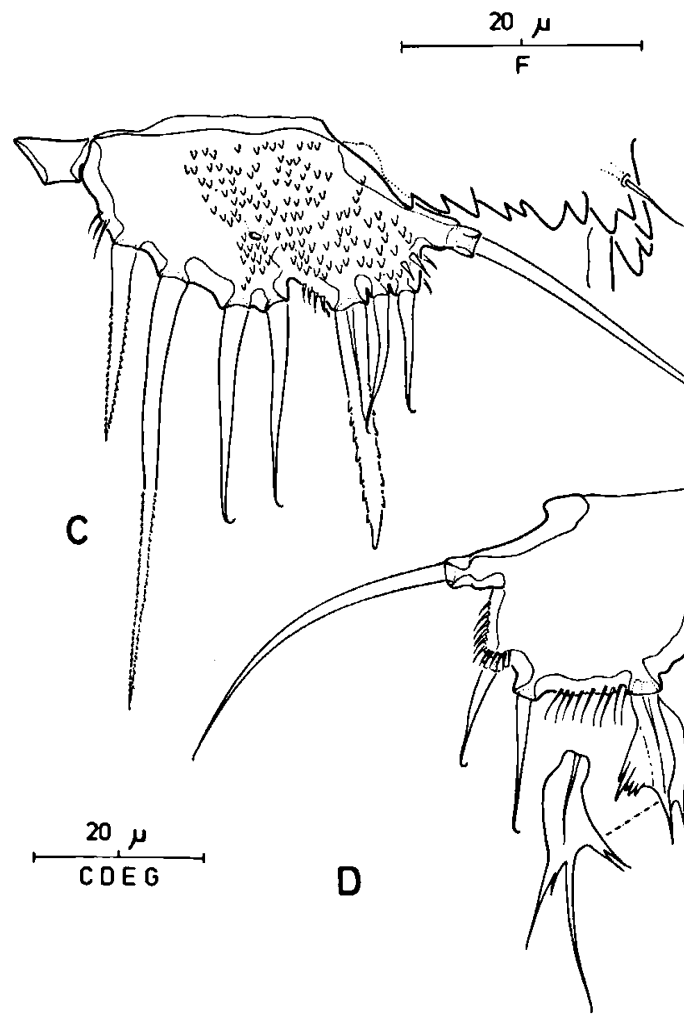
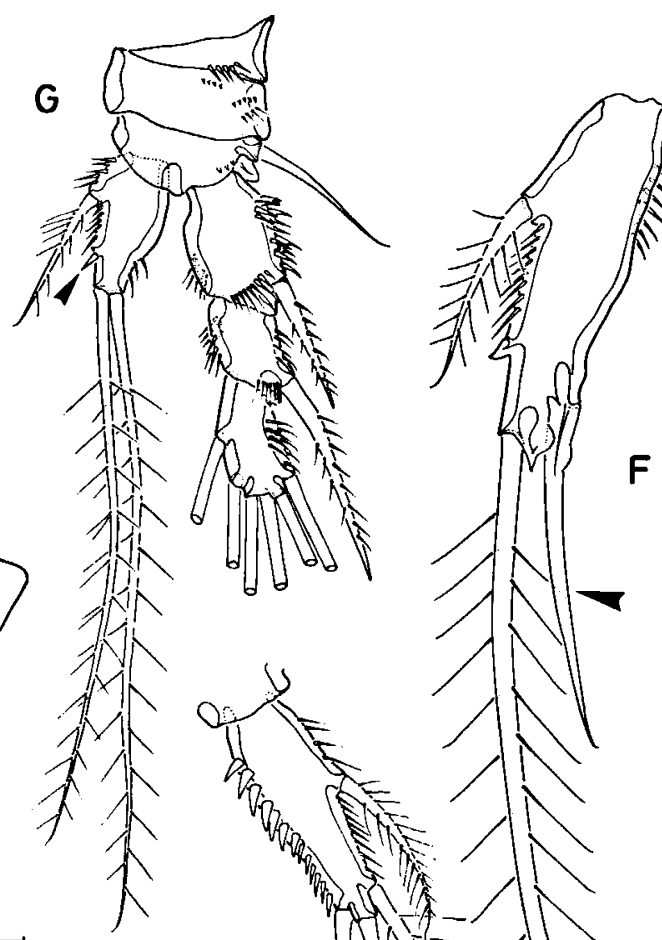

$\mathrm{E}$
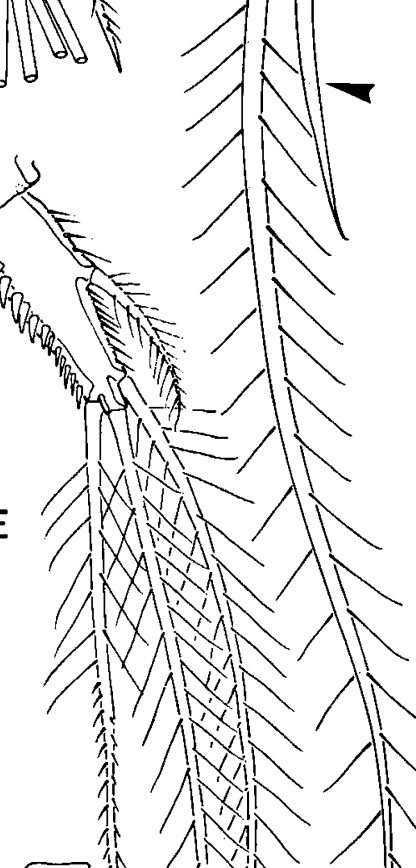
segment I with 2 patches of spinules in anterior half, with swollen, spinulose inner process and strongly developed, spinous outer process in posterior half; segment II with weakly developed, spinous outer process; segment IV swollen, inner half with complex ornamentation, outer half covered with diminutive spinules; segment $\mathrm{V}$ with backwardly directed apex and 2 basally fused setae. Setal ornamentation: I- 1 pinnate; II- $[8+2$ pinnate]; III-9; IV-[11 + 1 pinnate +3 modified + aesthetasc]; V-11.

Endopod of P2 (Fig. 13E) 1-segmented; outer margin with coarse spinules; distal inner seta much longer than in female; outer apical seta shorter than in female and pinnate along distal half instead of plumose.

Endopod of P3 (Fig. 13F) 1-segmented; with 1 apophysis and 2 setae in total; other 2 setae of female represented by minute spinous processes both apically and along inner margin; apophysis short, slightly curved and arising from outer margin (homologous with outer spine of female); outer margin with fewer spinules.

Exopod of P4 (Fig. 13G) with segments all considerably shorter than in female; outer and apical outer spines not swollen. Endopod a short swollen segment with 3 fully developed setae; distal inner seta vestigial, represented by setule.

Fifth pair of legs (Fig. 13C) not fused to supporting somite, rami fused but without clear distinction between endopodal and exopodal lobes, with remnant of intercoxal sclerite. Armature consisting of 3 pinnate spines and 5 naked setae; anterior surface with 1 secretory pore and numerous diminutive spinules.

Sixth pair of legs (Fig. 12A) strongly asymmetrical; represented on both sides by a small plate (fused to ventral wall of supporting somite along one side; articulating at base and covering gonopore along the other side) with 2 short setae at the outer corner. Free member covered with minute spinules. Only one gonopore is functional (the right one in Fig. 12A). One very large but slender spermatophore with long, curved neck (Fig. 10A), occupying $1 / 3$ of body length.

Remarks. - Petkovski's (1977) description of $C$. noodti causes some confusion as to the condition of the first pedigerous somite. According to his diagnosis the P1-bearing somite is "... unvollkommen mit der Kopfregion verschmolzen" which is a very primitive trait within the harpacticoids since it is found only in the Canuellidae, Phyllognathopodidae, Chappuisiidae, some Latiremidae (Huys \& Kunz, 1988) and in the families of the Cervinioidea (Huys, 1988c). Petkovski's lateral view of the animal (Fig. 2: 60) however clearly shows that the first pedigerous somite is completely incorporated into the cephalothorax, and the present redescription revealed that he has misinterpreted the hyaline zone posterior to the transverse constriction of the cephalothorax. In contrast to Cristacoxa and Noodtorthopsyllus, the apophysis found on the male P3 endopod in Cubanocleta arises from the outer margin instead of the inner margin. Searching for the equivalent structures in the respective females revealed that both apophyses are not homologous. The Cubanocleta-type is derived through transformation of the outer spine of the female. This is corroborated by the fact that this seta is missing in the other genera which have also no outer apophysis in the male. Here, the inner apohysis is homologous with the proximal inner seta (Figs. $7 \mathrm{E}-\mathrm{F}$ ) of the female. This structure as well as the loss of the outer apophysis represent novel characters for the genera Cristacoxa and Noodtorthopsyllus. Conversely, the retention of the outer apophysis in Cubanocleta is of major phylogenetic importance because it allows for inclusion of the family in the Laophontoidea (see below). The genus can be easily differentiated from its congeners by the long outer process on the first antennular segment, the unisegmented P2 endopod, the sexual dimorphism on endopods of $\mathrm{P} 2-\mathrm{P} 4$, the structure of the female genital complex and the ornamentation of the caudal rami.

Discussion. - The Cristacoxidae are placed in the superfamily Laophontoidea (see below) on the basis of the following synapomorphies: (1) antennules with outer spinous process on segment 2 ; (2) antenna with allobasis; (3) P1 exopod without inner seta on exp-2 and 4 setae on exp-3; (4) P1 endopod 2segmented with elongated enp-1 and 2 elements on 
enp-2; (5) P2-P4 with 1- or 2-segmented endopods; exp-1 without inner seta; (6) sexual dimorphism of P3 endopod (outer apophysis; retained only in Cubanocleta); (7) P6 bisetose with one member fused to somite.

The new family is remarkable in the structure of the fifth leg. This limb is represented by a single plate bearing the same number of setae/spines in both sexes which is unique among harpacticoids (except for those forms which have highly reduced fifth legs, e.g. Rotundiclipeidae; Huys, 1988c). Males of Cristacoxidae basically do not differ from females in the P5 structure, suggesting that there has been an arrest of development of this limb prior to the appearance of sexual dimorphism in the young stage of the cristacoxid ancestor. In other words, adult Cristacoxidae might have retained a sexually indifferent leg 5 through retardation in the ontogeny of this limb. An indication of neotenous evolution is given when conformity exists with the larval stages of another taxon. Within the Laophontoidea the most plesiomorphic condition for the P5 is found in the Laophontidae, Laophontopsidae and Orthopsyllidae: the maximum number of exopodal setae is 6 for the females and 5 for the males; the maximum number of endopodal setae is 5 for the females and 2 for the males. In Cristacoxidae 8 setae are found of which the outer one represents the basal seta. Figure 14 summarizes the postembryonic development of the fifth leg in both sexes of an as yet undescribed species of Orthopsyllus from the Great Barrier Reef. This series proceeds in four sequential stages to adult legs having the maximum complement of armature and therefore can be regarded as an ancestral ontogeny. Comparison between the sexes reveals that the onset of sexual dimorphism appears in copepodid V, resulting in differences not only in size and shape, but also in number of armature elements. If we go through the ontogenetic stages in a reverse order, copepodid IV is the first that displays a morphologically indifferent P5. Furthermore, in this stage the total number of setae is 7 (excluding the basal seta) which is in complete accordance with the adult condition of the Cristacoxidae. This parallel between ontogeny and phylogeny strongly suggests that the adult P5 in this family originated through hetero- chronic events, i.e. as a result of a developmental arrest in copepodid IV. The hypothesis that the cristacoxid condition must have arisen from an ancestral ontogenetic sequence leading to the maximum armature complement is corroborated by the P5 in the sister group of the Cristacoxidae, the Laophontopsidae (see below), which have retained the maximum setation as well. It follows that the weakly defined lobes found in the female P5 of $C$. noodti are not homologous with the exopodal and endopodal lobes.

In addition to the cristae on the precoxa and coxa of P1, Cristacoxidae are characteristic in having a uniramous mandibular palp and a specialized claw on the (proximal coxal) maxillary endite, and in lacking the antennary exopod. The latter character led Petkovski (1977) to assume possible affinities with the Ancorabolidae but the gross morphology of the other limbs excludes such a relationship. The Cristacoxidae have retained the spinous outer process on the second antennular segment, though it is often weakly developed, but more obvious is a similar structure on the first segment which in some genera (Cubanocleta) can attain a considerable size. Spinous processes on this segment are relatively rare within the Harpacticoida. Paramesochra dubia T. Scott exhibits an inner process, but most examples are found in the Laophontidae (e.g. Galapalaophonte Mielke). The latter family however, differs profoundly in the morphology of leg 1 and in the presence of an antennary exopod. The design of the cristacoxid P1 suggests strong affinities with the Laophontopsidae. These are corroborated by two important synapomorphies: (1) the sexual dimorphism of the P3 endopod, involving the loss of the inner seta and of the distal segmentation, (2) the male antennule with segments fused distal to geniculation.

The ancestral 2-segmented condition of the endopods of P2-P4 (cf. laophontoidean ancestor) is retained only in the P2 of Cristacoxa and Noodtorthopsyllus. The proximal segment bears a short pinnate seta at the inner margin which is also found in the following legs. Therefore, the unisegmented endopods of P3 and P4 are derived by fusion and not through reduction of the proximal segment.

Males of Cristacoxidae can be readily recognised 


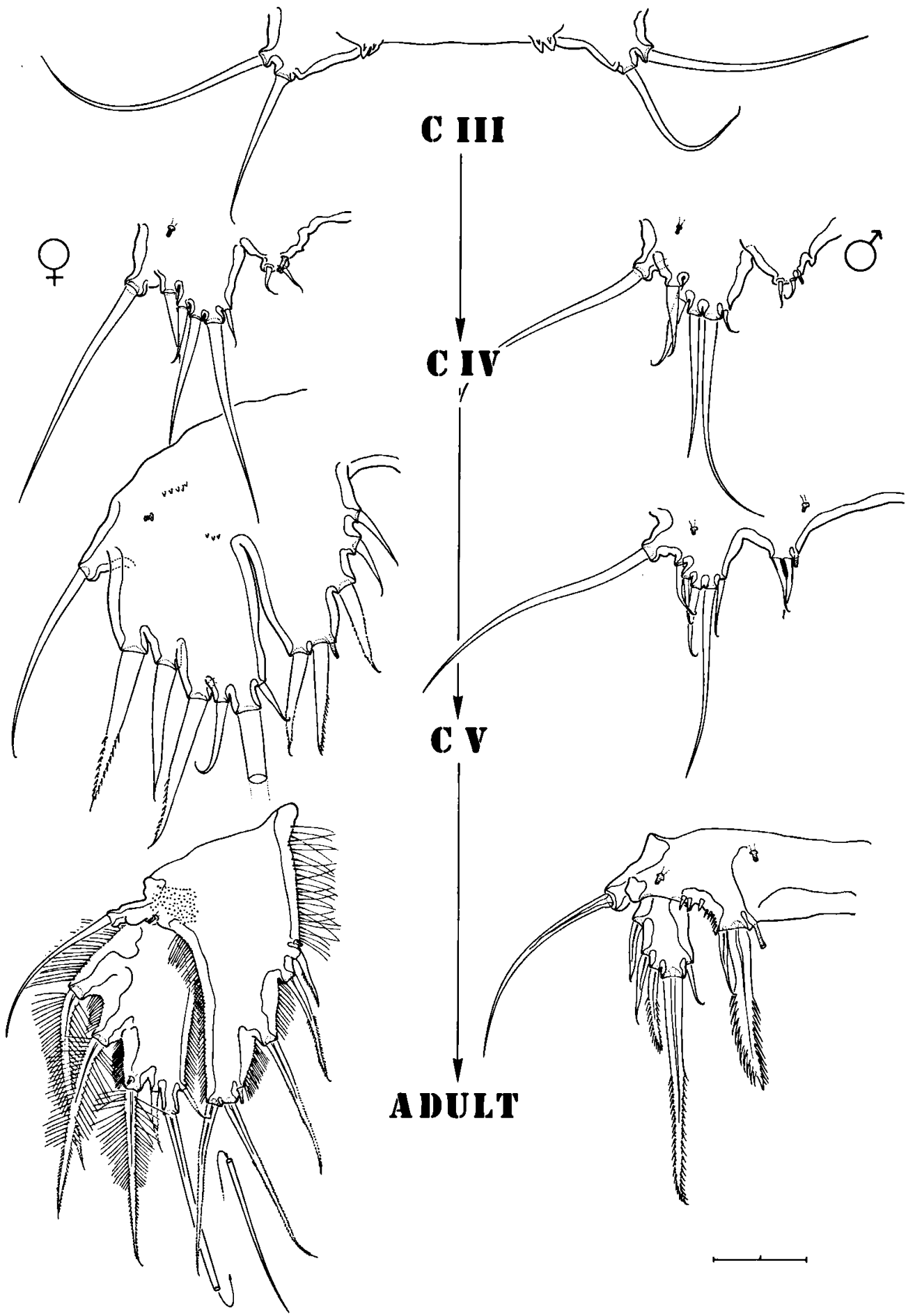

Fig. 14. Orthopsyllus spec. Postembryonic development of the P5 in both sexes. Scale-bar: $20 \mu$ (except for adult female P5: $40 \mu$ ). 
by their extremely large spermatophore which usually attains over $1 / 3$ of the total body length. The precocious clasping mode is similar to that found in the Laophontopsidae (observation of $C$. noodti from the Galápagos): the male grasps the setae of the female's caudal rami by means of its prehensile antennules.

The current distribution of the family is confined to the Atlantic Ocean with the exception of the find of $C$. noodt $i$ in the Galápagos. The family seems to be widely distributed in the Caribbean with records from Cuba, Bonaire, Curaçao and Klein Curaçao and has a second centre in the Canary Islands. $C$. noodti has a discontinous distribution with populations on both sides of the Isthmus of Panamá. Mielke (1981a, 1982, 1983, 1984b, 1985) already pointed out the existence of amphi-American interstitial harpacticoids. Cristacoxidae are genuine mesopsammic copepods, crawling and swimming in the labyrinth of interstitial spaces between the sand particles as is exemplified by their adaptations such as their small size and the cylindrical body form with the cephalothorax slightly broader than the succeeding somites. They preferably inhabit marine and brackish sub-soil water ("Küstengrundwasser"').

2. The concept of the superfamily Laophontoidea T. Scott

Lang (1944, 1948) was the first to recognise suprafamilial taxa within the order Harpacticoida. The Cletodidae T. Scott, Laophontidae T. Scott and Ancorabolidae Sars were grouped in his "Cletodidimorpha" on the basis of a suite of confusing characters which vary quite extensively from one genus to another. Of these, the presence of sharply defined somites is in fact the only feature which is more or less consistent within the three families. Lang gave the Cletodidimorpha superfamilial rank and it was not until very recently (Bowman \& Abele, 1982) that the taxon name was amended using the now accepted ending -oidea. Lang's (1948: 1470) phylogenetic scheme of the Cletodoidea presents an ill-defined grouping of families and has no taxonomic merit. The Laophontidae were placed in association with the Ancoraboli- dae on account of the prehensile endopod of $\mathrm{Pl}$; the non-prehensile P1 of certain genera, particularly the Ancorabolinae Sars, was considered by Lang (1948) as being a secondary condition evolved through reduction of the prehensile precursor.

Por (1986), having attemped a re-evaluation of the Cletodidae, rightly concluded that the Cletodoidea in its Langian sense has no right of existence. As a result he coined the superfamilial name Laophontoidea to accommodate the Laophontidae and the Ancorabolidae but unfortunately he did not diagnose the taxon.

Before redefining the Laophontoidea, it is of major importance to deal first with its nominate family. T. Scott (1905) proposed the family name Laophontidae however, did not define the boundaries of the taxon. Conversely, Lang $(1944,1948)$ contributed a lot in shaping the family by subdividing it in three subfamilies: Laophontinae, Normanellinae Lang and Donsiellinae Lang. The Laophontinae included the bulk of the genera and was defined primarily on the basis of the fused rostrum and the outline and ornamentation of the P1. Despite the description of various new genera during the last few decades (e.g. Cottarelli, 1977; Cottarelli et al., 1983, 1985; Fiers, 1986; Mielke, 1981b, 1985; Pallares, 1975), these characters (and others) still prove to be highly diagnostic. The most important exceptions to these rule are the genera Sarsocletodes Wilson and Pholenota Vervoort. Lang (1948) supposed affinities between Sarsocletodes and Platychelipus because of the short endopod of leg 1 but this view was refuted recently by Huys (in press b). Whilst retaining the latter genus in the Laophontinae, this author transferred Sarsocletodes to the Adenopleurellidae, a newly established family encompassing also the new genera Adenopleurella Huys and Proceropes Huys, as well as the ex-cletodid Miroslavia Apostolov. The Adenopleurellidae typically have paired, lateral glands on the cephalothorax and all but one (P4) of the body somites. Comparison with the postembryonic development of real laophontids revealed that the juvenile appearance of the adenopleurellid $P 1$ is not attributable to heterochronic events within the Laophontidae. The tentative allocation of Pholenota to the Laophontidae (Vervoort, 1964) 
was based primarily on an erroneous interpretation of the segmentation of leg 1 . Re-examination of the holotype (Huys, in press a) demonstrated unequivocally that $P$. spatulifera is merely a specialized diosaccid, a view already hinted at by Vervoort (1964). Recently, the Namakosiramiidae Ho \& Perkins, a former cyclopoid family (Ho \& Perkins, 1977; Ho, 1986), was included in the Harpacticoida and subsequently relegated to a synonym of the subfamily Laophontinae (Huys, 1988a).

The second subfamily, the Donsiellinae, was established by Lang $(1944,1948)$ to accommodate the gribble-associated Donsiella limnoriae Stephensen. Hicks' (1988) excellent paper on the systematics of the Donsiellinae resulted not only in the description of several new taxa, but also in the removal of the entire subfamily from the Laophontidae. Hicks placed the Donsiellinae in the heterogeneous Thalestridae (for discussion, cf. Huys, in press d), recognizing their closest affinities with the Pseudotachidiinae Lang, an opinion concurred with by the present author (Huys, 1988a). The familial diagnosis of the Laophontidae was further narrowed considerably by the removal of the Normanellinae, an amalgam of "laophontid-like" genera for which no taxonomic nor phylogenetic unity could be proved (Huys \& Willems, 1989). The major result of all these actions is that the Langian Laophontinae are elevated to full family status and that with the exception of Laophontopsis Sars none of the genera of the other two subfamilies bear any direct relationship to the Laophontidae.

Apart from the nominate family Laophontidae, four other families can be assigned to the Laophontoidea: Adenopleurellidae Huys, Laophontopsidae Huys \& Willems, Orthopsyllidae Huys, and Cristacoxidae fam. nov. According to Huys \& Willems (1989), the Laophontopsidae include the type genus Laophontopsis, formerly belonging to the Normanellinae, and the new genera Telodocus Huys \& Willems and Aculeopsis Huys \& Willems. The family Orthopsyllidae was established (Huys, in press c) to accommodate Orthopsyllus Brady \& Robertson (ex Canthocamptidae) and the newly erected genera Dionyx Huys and Infrapedia Huys. The Laophontoidea can be defined unequivocally on the basis of the following suite of diagnostic apomorphies which shows a sufficient complexity to warrant the monophyletic status of the superfamily.

\section{a. Antennula (apomorphy 1)}

The female antennule of the laophontoidean ancestor is 8-segmented in the female. This plesiomorphic condition is retained only in some Laophontoidea. Some species of Paralaophonte Lang display 8 antennular segments in the females (Monard, 1934; Nicholls, 1944; Pallares, 1968) but this number is also recorded for some representatives of Paronychocamptus Lang (Sars, 1905; Pallares, 1979) and an indistinctly 8-segmented antennule was reported by Noodt (1958) for Coullia platychelipusoides (Noodt, 1958). However, in most Laophontidae fusion takes place posterior to the aesthetasc-bearing segment IV resulting in short, oligo-segmented antennules. Whereas $7 \mathrm{seg}$ ments are still commonly found among certain laophontid genera such as Heterolaophonte Lang (e.g. Chislenko, 1976; Mielke, 1982; Letova, $1982^{* *}$ ) and Chilaophonte Mielke (Mielke, 1985), a 4-segmented antennule is apparently the rule in the other laophontoidean families. This condition is attained by fusion of the ancestral segments III-IV and V-VIII and has arisen independently within the Laophontidae, i.e. in Laophonte Philippi and a few other genera.

A character of central importance is the presence of a thorn-like process at the outer margin of the second antennular segment in both sexes [apomorphy 1]. This proces is found in all Adenopleurellidae, Orthopsyllidae, Laophontopsidae and Cristacoxidae although in the latter two families it might be reduced (Cristacoxa) or have lost its thorn-like shape (Laophontopsis). The vast majority of the Laophontidae also possesses this spinous structure. The fact that it is absent in non-related genera (Esola Edwards, Heterolaophonte, Namakosiramia Ho \& Perkins) indicates that the loss has been acquired

\footnotetext{
**The species name Heterolaophonte wellsi Letova, 1982 is preoccupied by Heterolaophonte wellsi Hamond, 1973. Wells et al. (1982) subsequently allocated Hamond's (1973) species to Quinquelaophonte Wells, Hicks \& Coull. I propose the substitute name $H$. letovae spec. nov. for Letova's specimens.
} 
convergently at different occasions in the evolution within the family rather than that the process itself evolved several times. The outer thorn-like process on the second antennular segment is therefore a synapomorphy for the Laophontoidea as a whole. Some genera have developed similar processes on the first segment (Cubanocleta, Laophonte, Galapalaophonte, Esola) but these are not significant at the suprafamilial level.

\section{b. Antenna (apomorphies 2 and 3)}

The antennary design provides a double apomorphy. In all Laophontoidea the basis and first endopod segment are fused into an allobasis which typically bears 1 seta at the abexopodal margin [apomorphy 2]; the abexopodal seta is secondarily lost in the Cristacoxidae and in the genera Novolaophonte Cottarelli, Saporito \& Puccetti (Cottarelli et al., 1983) and Afrolaophonte Chappuis (Mielke, 1981b, 1985). The quadrisetose, unisegmented exopod [apomorphy 3] might be a character adopted at an evolutionary lower level than the laophontoidean ancestor, however, pending more information on the outgroup of the Laophontoidea, it is treated here as a synapomorphy of the superfamily. The Cristacoxidae (no exopod) and the Adenopleurellidae (bisetose exopod) have undergone further reduction whereas the Laophontopsidae and Orthopsyllidae without exception have retained the quadrisetose condition. Conversely, the Laophontidae show a great deal of variation in setation (e.g. Heterolaophonte serratula Mielke, with 2 setae; Asellopsis intermedia (T. Scott), with 3 setae) although the great majority exhibits the ancestral state.

\section{c. PI exopod (apomorphy 4)}

The 3-segmented exopod never possesses an inner seta on the first two exopod segments and the distal segment primitively bears 4 armature elements [apomorphy 4]. The nature and detailed morphology of these elements can vary among the families. Laophontidae typically have 2 outer spines and 2 geniculate setae on this segment. Cristacoxidae always show 4 geniculate setae in contrast to the
Adenopleurellidae which have 1 geniculate and 3 simple spines. The laophontid arrangement which is also found in the Laophontopsidae is likely to be the ancestral one.

\section{d. PI endopod (apomorphy 5)}

The endopod is primitively 2 -segmented and consists of an elongate proximal segment and a short distal one bearing 2 armature elements, the articulation sites of which overlapping each other in anterior aspect [apomorphy 5]. Adenopleurella brevipes Huys and Miroslavia longicaudata Apostolov are the only species having a 1-segmented endopod. The first segment possesses an inner seta which is retained only in the Laophontopsidae and some Cristacoxidae (Noodtorthopsyllus). The nature of the distal armature elements are highly diagnostic at the family level (Fig. 15). Laophontidae typically have a strongly developed anterior claw and a diminutive posterior setule. Adenopleurellidae primitively possess a bipinnate anterior spine and a short posterior seta. Cristacoxidae and Laophontopsidae (Aculeopsis, Telodocus) primitively have a slender anterior claw and a geniculate posterior seta. A long, serrate anterior claw and a complex posterior brush seta are found in the Orthopsyllidae. It is postulated that the ancestor had 2 geniculate setae on this segment which have undergone various modifications in the different lineages. Only the Orthopsyllidae have retained the geniculate character in both armature elements.

Jakobi's $(1953,1954)$ claims of a 3-segmented endopod in Loureirophonte catharinensis Jakobi, $L$. paranaensis Jakobi, Mourephonte catharinensis Jakobi, and in the male of Heterolaophonte manifera sulamericana Jakobi are erroneous (Lang, 1965).

\section{e. P2-P4 (apomorphy 6)}

The P2 to P4 have at most 2-segmented endopods [apomorphy 6] but in numerous species of the Laophontidae and in some Cristacoxidae fusion of the constituent segments occurs. In Namakosiramia and a few interstitial representatives of the Laophontidae (e.g. Laophontina Norman \& T. Scott 


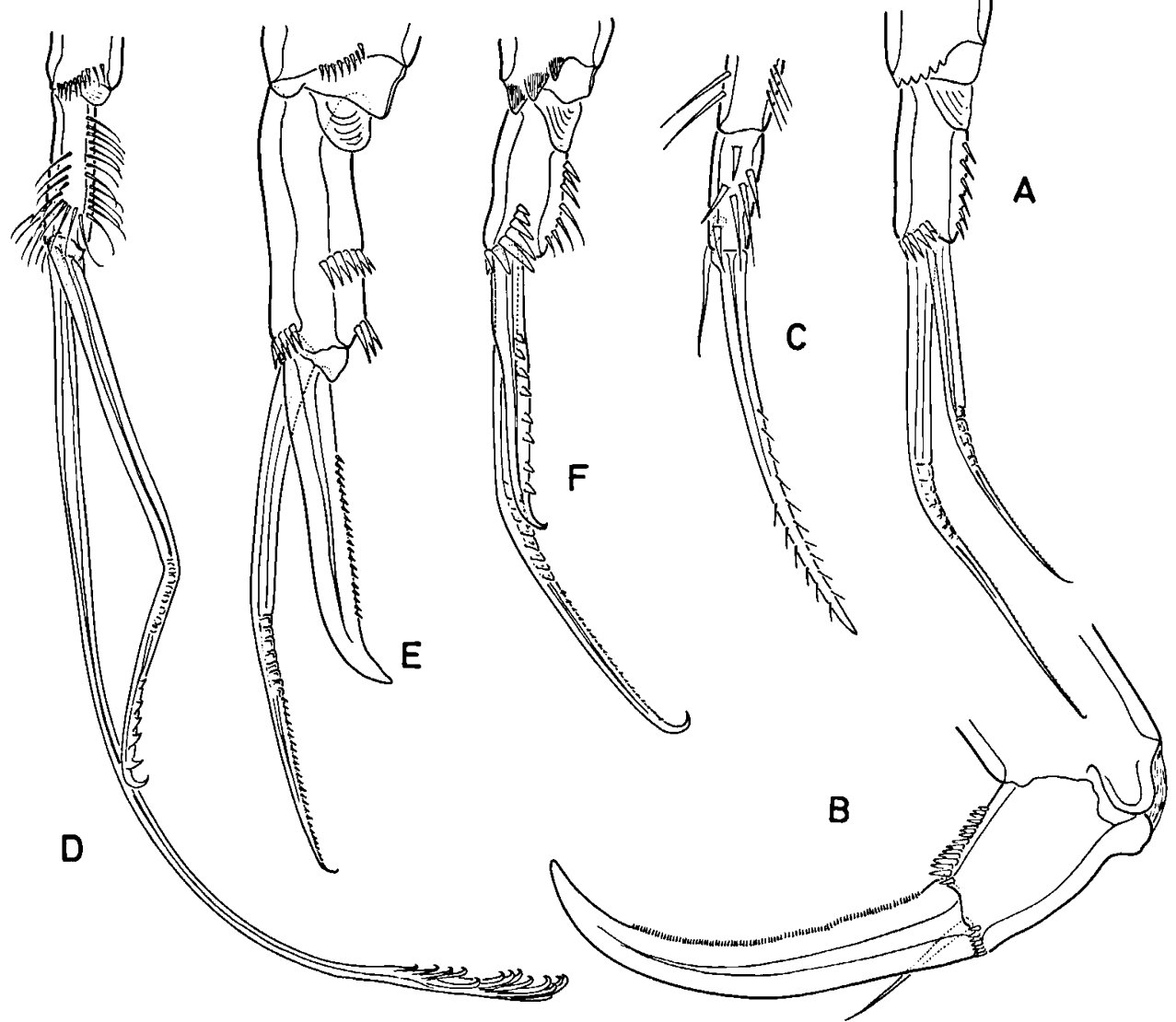

Fig. 15. Armature of distal endopod segment of leg 1 in the various families of the Laophontoidea; anterior view. A, Hypothetical ancestral condition; B, Laophonte cornuta Philippi, 1840 (Laophontidae); C, Sarsocletodes typicus (Sars, 1920) (Adenopleurellidae); D, Orthopsyllus sarsi Klie, 1941 (Orthopsyllidae); E, Aculeopsis longisetosus Huys \& Willems, 1989 (Laophontopsidae); F, Cubanocleta noodti Petkovski, 1977 (Cristacoxidae). (Different scales.)

(part.), Afrolaophonte) some of the endopods can be completely absent. The presence of 3-segmented endopods in P2-P4 is an insurmountable obstacle to place Pholenota spatulifera in the Laophontidae (Vervoort, 1964; Huys, in press a). The proximal exopod segment never bears an inner seta in P2 to P4.

\section{f. Sexual dimorphism of P3 endopod (apomorphy 7)}

This is a particularly robust character [apomorphy 7] because it involves the position of sexual dimorphism on the correct leg and ramus, and the evolution of an outer apophysis in the male. How this apophysis develops during ontogeny is depicted in Fig. 16 using the last four stages of a copepodid series of Orthopsyllus spec. from the Great Barrier Reef. The endopod is represented by a small, bisetose segment in copepodid III and the onset of sexual dimorphism appears in the following stage. It shows how the outer setule is already modified into a straight pinnate process in the male C IV. In the succeeding stages this process further develops to a robust two-barbed apophysis in the adult male. The parallel female sequence demonstrates how the small outer setule develops into the large outer spine of the adult female. Barnett (1966), in his comparative study of the larval stages of Platychelipus littoralis Brady and P. laophontoides Sars, obtained similar results. Barnett showed how sexual dimorphism becomes apparent in copepodid IV. In 


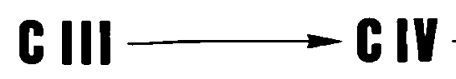
C V $\longrightarrow$ A D U L T
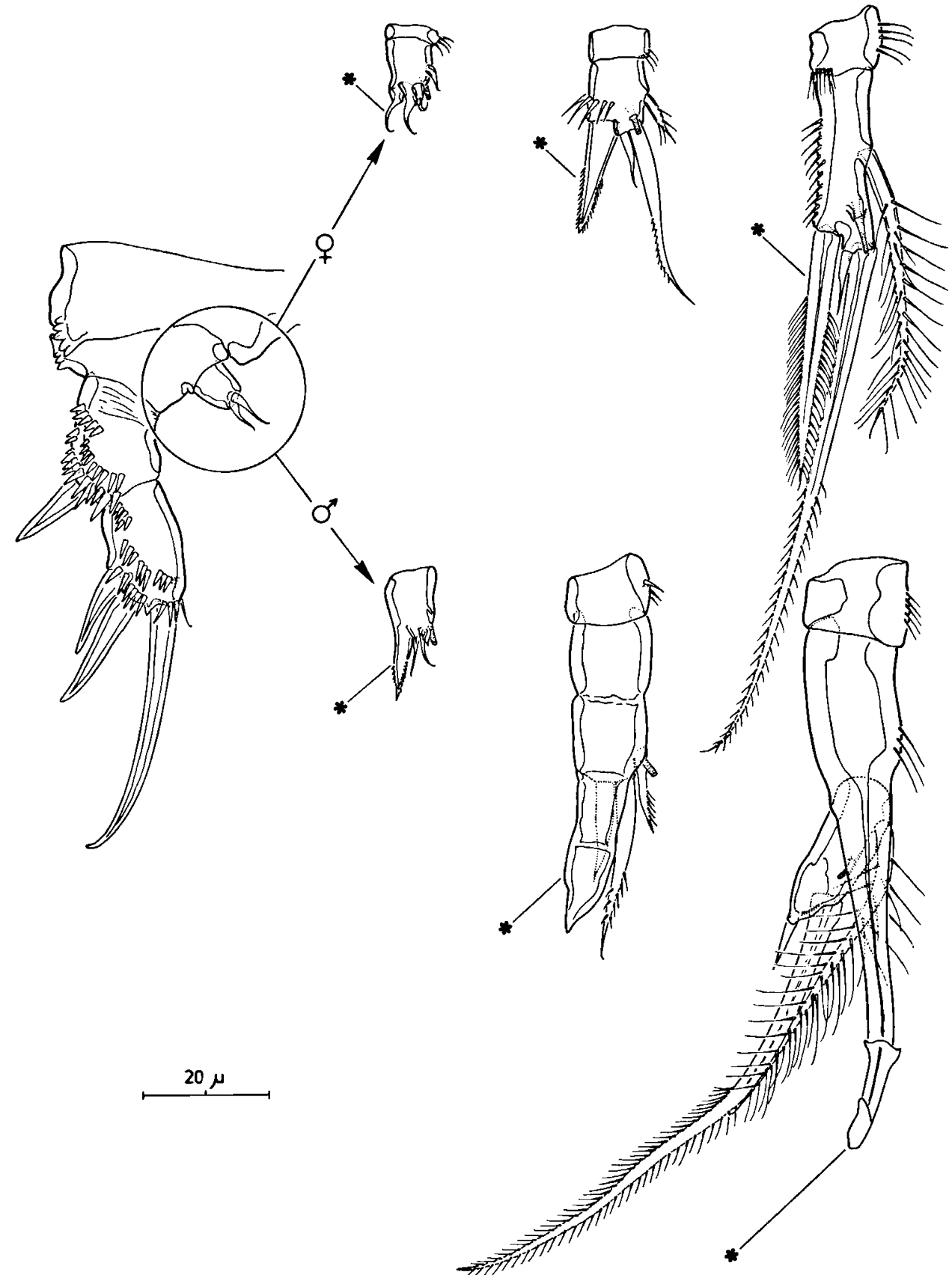

Fig. 16. Orthopsyllus spec. Postembryonic development of the endopod of leg 3 in both sexes (asterisks showing homologous structures in succeeding stages and between sexes; initial stages of P3 in C I and C II not drawn).

males of both species the distal segment at this stage is modified on the outer corner into a pointed projection.
The male apophysis of the Laophontoidea can be unequivocally defined as the homologue of the female outer spine. It follows that this type of sexual 
dimorphism is absent in species whose females have no outer spine on the distal endopod segment of P3 (unless the female development is retarded, see $\boldsymbol{P}$. littoralis; Barnett, 1966). This is exemplified in the Laophontidae by e.g. Echinolaophonte tetracheir Mielke, Loureirophonte isabelensis Mielke, Paralaophonte aenigmaticum Wells, Hicks \& Coull and Lipomelum heteromelum Fiers. The loss of the outer apophysis is also documented in the Cristacoxidae by the genera Cristacoxa and Noodtorthopsyllus. As pointed out before the inner apophysis found on the same limb in the latter genera is not homologous.

In some genera the outer apophysis is directed either ventrally or adaxially because of its sigmoid shape (e.g. Orthopsyllidae); this can cause difficulties in the interpretation of the structure in mounted specimens. In the Orthopsyllidae, Adenopleurellidae and many primitive Laophontidae (Laophonte, Esola, ...) the evolution of the apophysis has resulted in a three-segmented endopod in the male by separation of the distal half of enp-2. This condition is interpreted here as being the plesiomorphic one.

\section{g. Male P6 (apomorphy 8)}

This is also a compound character involving [apomorphy 8] the reduction of the armature and the evolution of the asymmetrical design. The postembryonic development of the male P6 and its equivalent in the female are illustrated in Fig. 17 and are observed from specimens of Orthopsyllus spec. The rudiments of the sixth legs appear in the fourth copepodid and consist of two bisetose processes on either side of the ventral midline. The females differ from the males in the succeeding stage in the presence of an extra seta and of a row of minute spinules on either side. The female genital complex appears at the final moult. The trisetose protuberances of the P6 aid in closing off the gonopores and the tiny spinular row is now involved in the locking mechanism of the genital slit. The male C V stages do not show any fundamental differences with the preceding copepodid except that the outer seta is somewhat longer, however they undergo characteristic changes during the final moult.
The adult male has retained the bisetose armature but the plate-like limbs (which are both defined at the base in most harpacticoids) are bilaterally asymmetrically arranged: one member is fused to the ventral wall of the last thoracic somite, the other limb acts as a valve during spermatophore extrusion, covers the only functional gonopore and is located in an excavation of the ventral integument. In all families examined the male sixth pair of legs exhibit "dimorphic asymmetry" (see Ferrari, 1984). The members of the limb pair may be found in reversed positions on different animals and the position of the "valve" is in concordance with the development of either the left or right testis and vas deferens. In their ancestral state both limbs do not show considerable differences in shape and size (e.g. Esola) but generally the free member is smaller and rounder (cf. Cristacoxidae) whilst the fused member becomes entirely incorporated in the supporting somite. The Adenopleurellidae deviate from the ancestral condition since both limbs are fused at their base.

\section{h. Description of the laophontoidean ancestor}

In order to allow determining whether a particular character or its alternate homologue is the apomorphic character, a diagnosis of the hypothetical ancestor common to all Laophontoidea is necessary. This ancestor will be applied in the out-group comparison when testing the relationships between the various subtaxa. It is assumed that evolution went primarily towards quantitative reductions both in segmentation and armature. The laophontoidean ancestor therefore combines the plesiomorphic states for each character found in the various families and is unequivocally defined on the basis of the 8 apomorphies outlined above.

Diagnosis. - First pedigerous somite completely incorporated in cephalothorax. Genital and first abdominal somites fused in female with fusion line demarcated by internal chitinous rim, ornamentation and by the posteriolateral corners of the constituent somites. Anal operculum moderately developed, pseudoperculum absent; anal opening exposed in dorsal aspect. Caudal rami with 7 setae. 
C IV
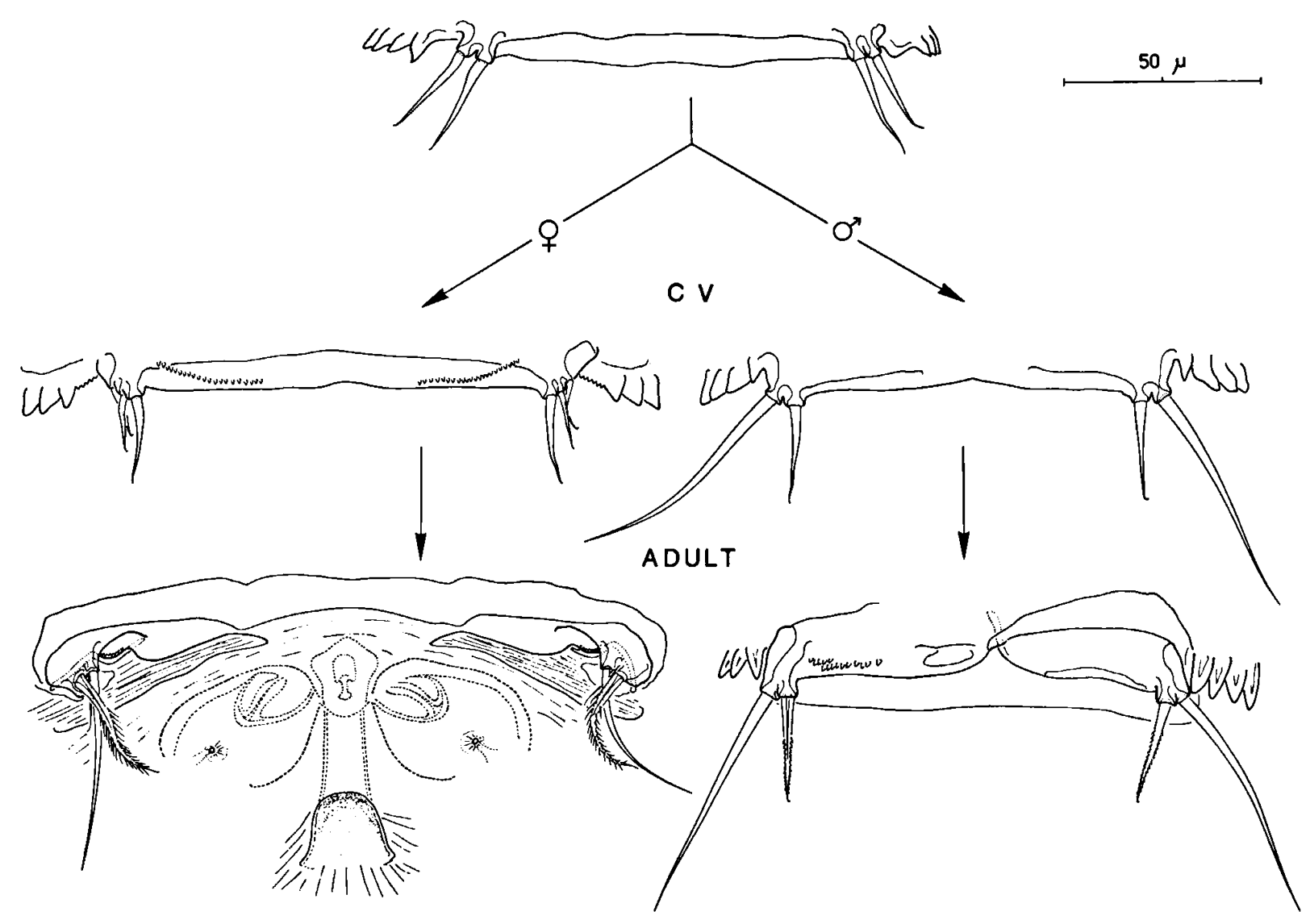

Fig. 17. Orthopsyllus spec. Postembryonic development of the sixth pair of legs in both sexes.

Sexual dimorphism in antennula, endopod P3, P5, P6 and in genital segmentation.

Rostrum defined at base; pore associated with frontal organ anteriorly positioned near rostral tip. Antennules with outer thorn-like process on segment II; ornamentation primarily consisting of pinnate spines and setae; 8 -segmented in female with aesthetasc on segment IV; 7-segmented and modified in male with geniculation between segments $V$ and VI and with aesthetasc on segment V. Antenna with allobasis bearing 1 abexopodal seta and quadrisetose, unisegmented exopod; endopod with 2 curved spines, 3 geniculate setae and 1 setule at the distal margin, with 1 curved spine and 1 setule at the abexopodal margin, with 1 pinnate spine on the abexopodal face. Labrum a simple lobe with few ornamentation. Mandible with biramous palp; basis with 2 setae; endopod defined, with 1 lateral and 3 apical setae; exopod represented by 1 seta. Paragnaths not fused, spinulose. Maxillula without epipodite; precoxal arthrite with 8 distal elements, 2 inner setae and 2 setae on anterior surface; coxa with 1 claw and 2 setae; basis with 2 endites, distal endite with 1 claw and 2 setae, proximal endite with 2 setae; endopod incorporated in basis, with 3 setae; exopod defined, with 2 setae. Maxilla with 3 endites on syncoxa, proximal endite vestigial and with 1 seta, middle and distal endites with 1 claw and 2 setae each; basal endite claw-like with 2 setae and 1 spine; endopod 1-segmented, with 3 setae. Maxilliped with syncoxa bearing 2 setae; basis asetose; endopod with long claw and 2 setae.

P1 to P4 with 3-segmented protopods and exopods, and 2-segmented endopods. Pl with basal 
spine standing at the inner margin; exopod without inner seta on exp-1 and exp-2, with 2 outer spines and 2 geniculate setae on exp-3; enp-1 elongate, with inner seta; enp-2 with 1 anterior and 1 posterior geniculate seta. P2-P4 with following seta and spine formula:

$\begin{array}{lll} & \text { Exopod } & \text { Endopod } \\ \text { P2 } & 0.1-1 . \text { I-1.1I.III } & 1.0-2.2 .1 \\ \text { P3 } & 0.1-1 . \text { I-2.1I.III } & 1.0-3.2 .1 \\ \text { P4 } & 0 . \text { I-1.I-2.1I.III } & 1.0-2.2 .1\end{array}$

Endopod of P 3 3-segmented in male; middle segment with outer apophysis being homologous with outer seta on enp-2 of female.

Fifth legs separate; baseoendopod with 5 setae in female, with 2 setae in male; exopod with 6 setae in female, with 5 setae in male.

Female genital complex with separate gonopores covered by rudimentary trisetose P6; copulatory pore distinct; seminal receptacles paired. Male P6 bisetose; bilaterally asymmetrical with one member fused to supporting somite and other member free, acting as a valve during spermatophore extrusion; showing dimorphic asymmetry.

One egg-sac. Spermatophore moderately sized. Male genital system unpaired. Males grasp females' caudal setae during precopulatory clasping.

\section{i. Phylogenetic implications}

Having re-defined unambiguously the concept of the Laophontoidea, neither Lang's (1948) phenogram of the Laophontidae, nor Por's (1986) proposal to unite the Laophontidae and Ancorabolidae in the Laophontoidea can be accepted.

None of the Ancorabolidae have a thorn-like outer process on the second antennular segment. It is unlikely that this novel structure has been reduced in the evolution of the Ancorabolidae because several other characters prove that they cannot have been arisen from the laophontoidean ancestral stock. Ancorabolidae share the antennary allobasis but several genera (Dorsiceratus Drzycimski; Ancorabolus Norman, Echinocletodes Lang) have 2 abexopodal setae on this segment (1 endopodal, 1 basal) instead of one. As a rule Ancorabolidae also are lacking an antennary exopod (except for Paralaophontodes exopoditus which has a vestigial one; Mielke, 1981b). The exopod of P1, when 3-segmented (e.g. Tapholaophontodes Soyer), usually bears 4 geniculate setae at the distal segment. The primitive condition of the 2 -segmented endopod is displayed by genera such as Laophontodes T. Scott (part.), Tapholaophontodes and Algensiella Cottarelli \& Baldari, which have 3 armature elements on the distal segment instead of 2 . The endopods of P2 to P4 are commonly reduced in the Ancorabolidae and are of no significance for this purpose except that they are at the most 2-segmented. The male endopod of P3 usually exhibits a short outer apophysis but the origin of this structure is different. The homology of the ancorabolid apophysis is illustrated by for instance Bodiou \& Colomines' (1988) drawings of Tapholaophontodes laurenceae. Their Figs. $2 \mathrm{C}$ and $2 \mathrm{~F}$ clearly demonstrate that the outer spinous process is nothing more than an outgrowth of the outer margin of the segment, a character also found in some Cletodidae. Finally, the male sixth pair of legs is virtually absent in the Ancorabolidae; the only vestige is a small sclerite closing off either the right or left gonopore.

The Normanellinae were removed from the Laophontidae and raised to family rank for several reasons (Huys \& Willems, 1989). The family was provisionally divided in two subfamilies in order to reflect its heterogeneity. The Normanellinae, including only Normanella Brady, have many characters differentiating them from the Laophontoidea. In some species $(N$. bolini Lang, $N$. aberrans Bodin) the antennary basis and the first endopod segments are still completely separate. The exopod of the P1 differs considerably in the presence of an inner seta on exp-2, and 3 spines and 3 geniculate setae on the distal segment. Similarly, the endopod shows a different distal armature consisting of 1 claw, 1 geniculate seta and 1 setule. Some Normanellinae also have 3 inner setae on enp-2 P2 instead of 2 in the Laophontoidea (cf. $N$. bolini, $N$. confluens; Lang, 1965). Bodin's $(1968,1972)$ excellent drawings of $N$. aberrans and $N$. minuta Boeck(?) clearly illustrate that the male endopod P3 lacks a genuine apophysis although the outer seta is present in the female. The presence of 6 setae on the female baseoendopod of some species (N. con- 


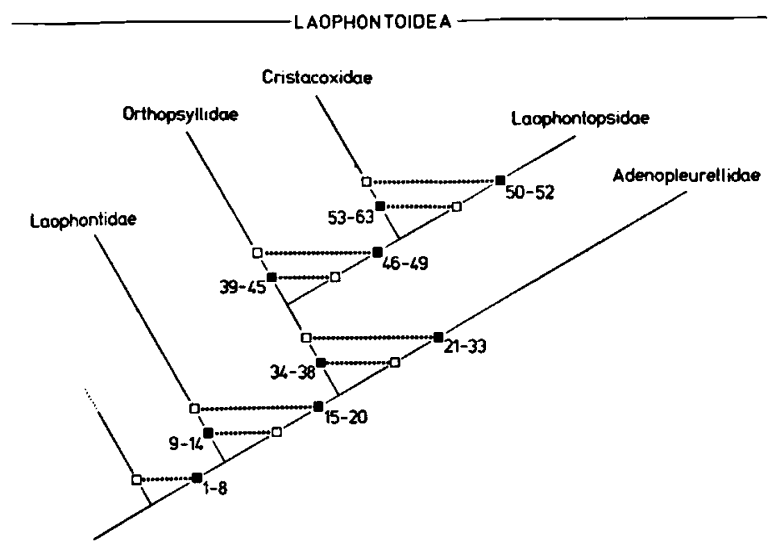

Fig. 18. Cladogram depicting the phylogenetic relationships within the Laophontoidea. Apomorphic ( 1 ) and plesiomorphic (ם) character states explained in the text.

fluens, $N$. porosa Noodt) also exclude the Normanellinae from the Laophontoidea. Finally, the male sixth pair of legs is definitely symmetrical in shape and arrangement, and moreover each plate is provided with 3 setae instead of 2 (except $N$. aberrans).

The Cletopsyllinae Huys \& Willems even differ in a greater extent from the Laophontoidea than the Normanellinaedo. The antennules exhibit 1-2 conical projections on segments I-II which are not homologous with the outer spinous process of the Laophontoidea. Some species of Cletopsyllus Willey have retained a separate basis in the antenna (cf. C. rotundifera Fiers). The mandibular basis as well as the maxillipedal syncoxa can possess up to 3 setae instead of a maximum of 2 in the Laophontoidea (cf. $C$. sagamiensis Itô). The first leg differs not only in the presence of an inner seta on the middle exopod segment, but also in the distal armature of the endopod which includes 1 claw, 1 geniculate seta and 0-2 minute setae. The P2 to P4 have a richer ornamentation than in the Laophontoidea: exp-1 P3-P4 with inner seta, exp-3 P4 with 3 inner setae, enp-2 P2 with up to 4 inner setae, enp-2 P4 with 3 inner setae. These differences alone make the allocation of the Cletopsyllinae to the superfamily impossible. Further differences are found in the male P5 which bears 3 setae on the endopodal lobe and in the male sixth pair of legs that, despite showing dimorphic asymmetry, deviates from the lao- phontoidean condition in possessing only 1 seta on each limb. Cletopsyllinae have also a slender apophysis on the male endopod P3, however this structure is homologous with the inner apical seta of the female.

3. A phylogenetic analysis of the relationships within the Laophontoidea T. Scott

The phylogenetic relationships of the various families are depicted in Fig. 18. Apomorphies 1 to 8 define the monophylum Laophontoidea and were already outlined above. Apomorphies 9 to 63 deal with the different clades that can be recognized within the superfamily and are pinpointed below.

\section{a. Laophontidae T. Scott 1905}

(9) Rostrum. The laophontid rostrum is typically fused to the dorsal shield of the cephalosome. However, Mielke (1981b, 1985) reported on several laophontids possessing a rostrum which is defined at the base. Re-examination of Laophonte galapagoensis Mielke, Loureirophonte isabelensis Mielke and $A$ frolaophonte schmidti Mielke revealed that the original boundary between the rostrum and the cephalosome, at least in situ, is indicated by a hyaline transverse band and not by a genuine articulation. This transparent zone is less sclerotized than the rest of the rostrum and therefore constitutes a predesigned breaking plane for the rostrum during dissection of the animal. This also explains why the dissected rostrum in most of these species shows an irregular basal margin opposed to the rounded contour found in the Laophontopsidae, Cristacoxidae and Orthopsyllidae where a genuine articulation occurs. The median pore of the frontal organ is found in its ancestral position, near the rostral tip (either slightly ventral or dorsal) flanked by the two sensillae as demonstrated, for instance, by Mielke's (1981b) detailed drawings of $L$. isabelensis (Fig. 6A), Heterolaophonte serratula Mielke (Fig. 11A) and Paralaophonte pacifica galapagoensis Mielke (Fig. 15A).

(10) Antennula. In general, the setae and spines of the female antennules show no ornamentation 
along their shaft. The richest ornamentation is found in Paralaophonte panamensis Mielke where pinnate setae or spines are present on the segments III and VI, however, this condition is still very reduced compared to the elaborate ornamentation of other Laophontoidea. The only other exceptions are consistently found on segment II where 1 or 2 plumose seta(e) can occur. The presence of smooth setae has arisen convergently in Sarsocletodes but the strongly ornamented antennule of Adenopleurella indicates that this condition evolved within the Adenopleurellidae. A similar reduction is found in the males though modified pinnate spines might be present on the inner margin of segment IV of some genera (see e.g. Lipomelum heteromelum; Fiers, 1986, Fig. 12b).

(11) Mandible. A maximum of 3 setae is found on the mandibular endopod opposed to 4 in the ancestral condition. The setation of the different parts of the mandibular palp is difficult to determine because in the majority of the Laophontidae the basis and the rami are fused to form a cylindrical segment with 1 outer and 1 inner seta and 3 apical setae. The latter 3 setae are derived from the endopod and this is supported by Mielke's (1981b) drawings of Galapalaophonte pacifica (Fig. 48A) and $P$. pacifica galapagoensis (Fig. 15C) in which the endopod represents a separate segment. It follows that the outer seta represents the exopod and that the inner one is derived from the basis. The most primitive palp is exhibited by Esola bulligera Farran in which 2 setae are retained on the basis and in which the trisetose endopod is also defined at the base (Vervoort, 1962). The other families of the Laophontidae have retained 4 setae on the endopod but only in the Cristacoxidae is the endopod demarcated from the base. The palp of the Adenopleurellidae is reminiscent of the cristacoxid one in lacking the exopodal and basal setation, however differs in segmentation. It is worthy to note that the retention of the ancestral endopodal complement excludes Sarsocletodes and allied genera from the Laophontidae.

(12) Maxillula. The structure of the laophontid maxillula presents a double apomorphy. The mar- ginal setation of the precoxal arthrite includes 7 apical (inner) spines, 1 dorsal and 1 ventral seta. Conversely, the 2 juxtaposed setae commonly found on the posterior surface of the arthrite in many other harpacticoids are definitely absent here, and their presence in the Laophontopsidae (Huys \& Willems, 1989) and in the Cristacoxidae (present account) suggests that this loss is an evolutionary novelty for the Laophontidae. The Laophontopsidae and the Cristacoxidae are the only Laophontoidea that have retained the two endites on the basis. The distal endite in these families bears 2 setae and a claw, the proximal endite is represented by 2 setae. All Laophontidae have lost the proximal endite. This character, despite its parallel evolution in the Orthopsyllidae and Adenopleurellidae, is a strict apomorphy for the family.

(13) Leg 1. The structure of the P1 is the major diagnostic character of the family and constitutes in fact a compound apomorphy (Huys, in press b): (a) outward migration of inner spine of basis to anterior surface, (b) basis produced into large pedestal for insertion of endopod, (c) loss of inner seta on enp-1, (d) posterior geniculate seta of enp-2 reduced to setule, (e) anterior geniculate seta of enp- 2 modified into large, non-geniculate claw. A slight displacement of the inner basal spine occurred convergently in the Cristacoxidae, but members of this family lack a well developed pedestal. The inner seta on enp-1 is retained only in the Laophontopsidae and in some genera of the Cristacoxidae (Noodtorthopsyllus), and has been lost several times in the evolution of the Laophontoidea. The short P1 endopod of Sarsocletodes cannot be attributed to heterochronic events within the Laophontidae and the reduction of the posterior geniculate seta to a setule in the Adenopleurellidae must be due to parallel evolution (Huys, in press b).

(14) Precocious clasping mode. Laophontidae display a unique mode of precocious coupling (Lang, 1948; Barnett, 1966; Hicks \& Coull, 1983; Dahms, 1988). The adult male grasps, by means of the antennules, the fourth legs of the (usually immature) female and assumes a position with the dorsal surface of the prosome adjacent to the ventral surface 
of the female urosome. There is evidence that the other families have retained the ancestral clasping mode (grasping the setae of the caudal rami) because it has been observed in the Laophontopsidae (Monard, 1935), the Cristacoxidae (present account) and in the Orthopsyllidae (Huys, unpubl.).

\section{b. Taxon Cristacoxidae - Laophontopsidae - Orthopsyllidae - Adenopleurellidae}

(15) Female antennula. All four families exhibit 4-segmented, short antennules in the female of which the constituent segments are fully homologous between the respective families. The ancestor of the Laophontidae is presumed to have eight segments because this number is retained in representatives of Paralaophonte and Paronychocamptus (e.g. Sars, 1905). The 4-segmented condition is then derived by fusion of segments III and IV, and segments V-VIII. As a result the aesthetasc is borne on segment III instead of IV in the Laophontidae.

(16) Male antennula. There is indication that the male of the laophontoidean ancestor possessed 8segmented antennules. This number is found in $G$. pacifica (Mielke, 1981b; pers. observ.) and is probably more common in the Laophontidae than previously expected. In $G$. pacifica the male antennule consists of 4 segments located anteriorly to the large, swollen aesthetasc-bearing segment (V), and three smaller segments (VI-VIII) which form the part posterior to the geniculation. Segment IV is a small disc with 2 setae, of ten concealed beneath the proximal part of segment $\mathrm{V}$. In the non-laophontid families segment IV is fully incorporated in the aesthetasc-bearing segment, resulting in a 7-segmented condition.

(17) Mandible. The basis (or the portion homologous with it) bears only 1 seta instead of 2 . A bisetose mandibular basis is found only in members of Esola (Vervoort, 1962; Mielke, 1981b), generally being recognised as very primitive Laophontidae.

(18) Leg 2. The four families have lost the outer seta on enp-2 of P2. This subdistal outer seta is retained only in the genus Esola and this character served
Lang (1948: 450) to define the genus as the earliest offshoot from the laophontid ancestral stock.

(19) Leg. 3. In contrast to the Laophontidae only 2 inner setae are found on enp-2 of P3 (in fact 2 setae are present only in the Adenopleurellidae; in the other three families only 1 inner seta is left). The ancestral number of 3 inner setae is very common amongst Laophontidae (see e.g. Lang, 1948; Table XXIV).

(20) Leg. 4. The endopod bears only 1 inner seta on its distal segment in all four families. In the Laophontidae 2 inner setae on enp-2 $\mathrm{P} 4$ are exhibited by species of Esola, Laophonte (cornuta-, serrata-, inornata-groups), Microlaophonte and Quinquelaophonte.

\section{c. Adenopleurellidae Huys}

(21) Pleural glands. All adenopleurellid genera have conspicuous, paired, lateral glands found on the cephalothorax and all but one (P4) of the body somites. Glandular modifications are also found in some species of Esola but these structures are not serially homologous (Huys, in press b).

(22) Rostrum. In contrast to the free rostrum of the [Cristacoxidae-Laophontopsidae-Orthopsyllidae]grouping, the rostrum of the Adenopleurellidae is fused medially to the cephalothorax. The posterior margin of the rostrum is clearly demarcated bilaterally from the dorsal shield and differentiates this semi-articulated rostrum from the laophontid condition. The rostral pore associated with the frontal organ is dorsally located, but posteriorly displaced compared to the ancestral position.

(23) Antenna. The exopod bears 2 setae instead of 4. The ancestral endopodal ornamentation is retained.

(24) Mandible. The mandibular palp consists of a cylindrical segment armed only with 3 apical and 1 lateral seta, representing the original endopodal setation. The uniramous palp evolved independently in the Cristacoxidae, however in the latter a clear 
boundary is still noticeable between the asetose basis and the quadrisetose endopod.

(25) Maxillula. The maxillulary exopod is a minute knob, incorporated in the basis and bearing 1 seta. The plesiomorphic state of this ramus is exhibited by the majority of the Laophontidae, and by the Laophontopsidae and Cristacoxidae where the exopod is represented by a distinct bisetose segment, fully demarcated at its base.

(26) Maxilliped. Two features of minor importance (because of their convergent evolution) can be found on the maxilliped. The ancestral number of 2 setae on the syncoxa is found in many Laophontidae. All known species belonging to the sister clade of the Laophontidae have only 1 seta, except for the orthousvllid Infrapedia coralliophila (Fiers) which has retained the plesiomorphic condition. This implies that the loss of one of the armature elements evolved several times independently within the superfamily, and that it can be regarded as an apomorphy for e.g. the Adenopleurellidae. A second remark involves the number of setae on the endopod. This character is difficult to quantify because of the small size of the armature elements. However, the ancestral number of 2 setae is still found in the Cristacoxidae. Huys (1988a) noted the presence of 2 dwarfed setae on the endopodal claw of Namakosiramia californiensis Ho \& Perkins and personal observations revealed that this number is common among Laophontidae as well although it has been rarely documented. The presence of only 1 seta on the maxillipedal endopod is an apomorphy for the Adenopleurellidae.

(27) Protopod Pl. A feature unique to the adenopleurellid genera is the adaxially produced inner part of the coxa. The inner and outer spine of the basis are located along their respective margins which is the plesiomorphic position retained from the ancestral laophontoidean stock. This condition is also found in the Orthopsyllidae and the Laophontopsidae.

(28) Exopod PI. This ramus presents a double apomorphy because of its segmentation and ornamen- tation. The 2-segmented exopod of P1 is a consistent character within the Adenopleurellidae. The ancestral 3-segmented condition is retained in all Orthopsyllidae, Laophontopsidae and Cristacoxidae. The distal exopod segment is furnished with 3 bipinnate spines and 1 inner, geniculate spine. This is an atypical configuration since in all other families this segment bears 2 spines and 2 geniculate setae.

(29) Endopod P1. The abbreviated endopod with its typical ornamentation is a diagnostic apomorphy for the family. The armature of enp-2 (if not fused with enp-1) consists of a bipinnate spine (which is homologous to the anterior claw of the Laophontidae) and a tiny setule (evolved through reduction of the posterior geniculate seta). The Adenopleurellidae also have lost independently the inner seta of enp-1 which is found in the Laophontopsidae and the Cristacoxidae.

(30) P2-P4. The Adenopleurellidae have lost the inner seta on the proximal endopod segment of P2 to P4. This seta is retained in the Cristacoxidae although this state might be obscured through fusion of the endopod segment of P3 and P4 (see Cubanocleta).

(31) Female P5. The armature of both rami is reduced in comparison with the other families (except Cristacoxidae) which have 6 setae on the exopod and 5 setae on the endopodal lobe of the baseoendopod. The Adenopleurellidae have 4 setae on the exopod and 3 on the baseoendopod.

(32) Male P5. A similar reduction is found in the male exopod which has 4 setae opposed to 5 in the Laophontidae, Laophontopsidae and Orthopsyllidae. The fifth legs are also fused medially in contrast to the Laophontopsidae, Cristacoxidae and some Laophontidae.

(33) Male P6. The sixth pair of legs has more or less retained its symmetrical outline as found in the primitive Laophontidae (e.g. Esola) but there is no trace of an articulation. The P6 is completely fused to the wall of the supporting somite and covers one functional gonopore. 


\section{d. Taxon Cristacoxidae - Laophontopsidae - Orthopsyllidae}

(34) Habitus. Species belonging to these families all have a cylindrical body without a clear demarcation between the prosome and urosome. In most Laophontidae and in the Adenopleurellidae there is an area of thin integument ventrally, immediately behind the insertion site of the P5, allowing for dorsal flexure of the urosome (see e.g. Adenopleurella brevipes; Huys, in press b, Fig. 1A). Such an area of flexible cuticle is not developed in the Cristacoxidae, Orthopsyllidae or Laophontopsidae. These families differ also from the others in lacking lateral processes on the genital double-somite. In Laophontidae and Adenopleurellidae the fusion of the genital somite and the first abdominal somite is indicated by a lateral incision on either side, often resulting in the development of (posteriorly directed) lateral processes with rich ornamentation. In some vermiform Laophontidae (Afrolaophonte, Klieonychocamptoides Noodt) these structures are also completely reduced but this happened secondarily in relation to their interstitial life style.

(35) Cephalothorax. A characteristic feature of the Cristacoxidae - Laophontopsidae - Orthopsyllidaegrouping is the presence of cuticular pits on the cephalothorax. These pits are interspersed with smooth areas and are often arranged in a typical, more or less symmetrical pattern. Adenopleurellidae lack these integumental depressions but some Laophontidae have them as well (e.g. Asellopsis Brady \& Robertson; Laophonte Philippi).

(36) Rostrum. The rostrum is completely defined at its base as in the ancestor of the laophontoidean core. The sensory pore associated with the frontal organ, however, is located at the ventral surface of the rostrum at a considerable distance from the tip.

(37) Antenna. The ancestral abexopodal armature of the endopod consists of: (a) 1 spine flanked by 1 setule implanted along the proper abexopodal margin of the segment, (b) 1 (often) bipinnate, spine on the abexopodal face. This number and arrangement is retained in the Laophontidae and
Adenopleurellidae only. In the other three families the accompanying setule is lost. Within this clade, the original arrangement of the remaining elements is retained only in the Cristacoxidae, i.e. 1 spine standing at the margin, 1 spine implanted on the surface. Through migration of the surface spine, both elements arise from the abexopodal margin in the Orthopsyllidae and the Laophontopsidae.

(38) Endopod P2-P3. The proximal inner seta which is commonly found on the distal endopod segment in Laophontidae and Adenopleurellidae is missing in the other families.

\section{e. Orthopsyllidae Huys}

(39) Maxillula. The bisetose exopod which is represented by a distinct segment is completely incorporated into the basis. The proximal endite of the basis is lost in the Orthopsyllidae but this has happened three times in the evolution within the Laophontoidea.

(40) Exopod P1. A major diagnostic character for the family is the presence of brush setae on P1 [see also apomorphy (41)]. The distal exopod segment possesses 2 brush setae equipped distally with recurved slender hooks. They are homologous with the geniculate setae of the Laophontidae and Laophontopsidae.

(41) Endopod P1. The inner seta on enp-1 found in the Laophontopsidae and some Cristacoxidae (Noodtorthopsyllus) is lacking in the Orthopsyllidae. Sars' (1909) drawing of this seta in Orthopsyllus sarsi Klie is based on a misinterpretation of the long spinules commonly found along the inner margin of the segment (Huys, in press c). The distal segment also shows an apomorphy because of the armature it bears: an anterior geniculate, distally pectinate, slender claw and a very long, weakly geniculate, brush seta.

(42) Exopod P2-P4. The armature on these rami is strongly reduced and represents a compound apomorphy. The middle exopod segments have lost the inner seta. The distal segments are lacking inner 
setae altogether whilst the inner apical seta is strongly reduced, representing at the most a vestigial setule which has regularly been overlooked in early descriptions.

(43) Endopod P2-P4. The proximal endopod segment is very reduced in this family. It is commonly broader than long and often represented by a small sclerite at the base of the endopod. The inner seta found in some members of the Cristacoxidae (cf. discussion) is lacking.

(44) Male endopod P2. Orthopsyllidae share the sexual dimorphism on the endopod of leg 2. It involves the reduction of the outer apical seta on the distal segment in the male. Females have 2 long setae apically except for Infrapedia coralliophila (Fiers) which possesses only one. Males of the latter species lack sexual dimorphism on this ramus, indicating that it is the outer seta that is lost in the female.

(45) Male P5. The baseoendopods of the fifth pair of legs are medially fused in the male.

\section{f. Taxon Cristacoxidae-Laophontopsidae}

(46) Male antennula. Male Cristacoxidae and Laophontopsidae consistently have a 5-segmented antennule. This reduction in number of segments is due to total fusion distal to the geniculation, this is distal to the swollen aesthetasc-bearing segment IV. A maximum of 7 segments (with 3 distal to the geniculation) is found in the sister group.

(47) Endopod PI. The anterior geniculate seta has developed into a pinnate, strong claw which shows no trace of any geniculation. The posterior geniculate seta is retained in the Cristacoxidae and Laophontopsidae (cf. Aculeopsis, Telodocus) but can reduce to a minute claw in the latter family (cf. Laophontopsis).

(48) Exopod P2-P4. The outer apical spine of the distal exopod segments of P2 to P4 is extremely elongate which makes it reminiscent of genuine setae. The pinnate ornamentation along the outer margin however indicates that these "setae" are homologous with the outer apical spines found in the Laophontidae, Adenopleurellidae and Orthopsyllidae. The modification went even further in the Cristacoxidae where also the outer spines have undergone strong elongation, hindering a correct interpretation of the spine- and seta formula.

(49) Male endopod P3. The phylogenetic significance of this structure is twofold. It involves reduction of armature during the ontogeny of the P3 since the inner seta of the distal segment found in the female is completely reduced in the male. Secondly, the formation of the outer apophysis does not result in a three-segmented condition of the ramus. Cristacoxidae and Laophontopsidae have a 2-segmented endopod in both sexes and the suppression of subdivision of the distal segment during the male postembryonic development is a novel character for this clade.

\section{g. Laophontopsidae Huys \& Willems}

(50) Caudal rami. Laophontopsidae are not easy to diagnose from a cladistic point of view, however they can be readily distinguished by their lamelliform caudal rami. The rami are dorsoventrally depressed, paddle-shaped appendages and their modification involves also the anterior displacement of the dorsal seta (VII) which is positioned near the oblique spinular row that delimitates the posterior margin of the pentagonal anal vestibulum. As a rule the other setae are strongly reduced as well, particularly the terminal ones (IV-VI). Some Laophontidae have also developed independently flattened caudal rami. The genera Asellopsis (e.g. Mielke, 1975) and Tapholeon Wells (cf. Wells, 1967) typically have non-cylindrical rami but these are not comparable, either because the distal armature is not reduced, or the dorsal seta is not positioned in the same place. Two species of Paralaophonte Lang also have lamelliform caudal rami $(P$. asellopsiformis Lang; $P$. aenigmaticum Wells, Hicks \& Coull) but these must be attributed to ecological convergence.

(51) Endopod P2-P4. A convergent loss of the inner seta on the proximal endopod segments P2-P4 has evolved in the Laophontopsidae. 
(52) Fifth legs. The position and shape of the fifth legs constitute another diagnostic apomorphy for the family. As shown by Huys \& Willems (1989) in both sexes the legs are strongly abaxially displaced, leaving a wide gap in between which is not occupied by an intercoxal sclerite (cf. Cristacoxidae). The shape of the P5 is also remarkable since both the exopod and the endopodal lobe represent cylindrical structures standing perpendicular on the transverse axis of the narrow basis. A final diagnostic feature is the presence of distally serrate spines ( 2 in female, 1 in male) along the inner margin of the endopodal lobe. The latter lobe is extremely well developed in the males which is also atypical within the Laophontoidea.

[Male endopod P2]. This might be a potential apomorphy but since it is based on one species only, it is not applied in the cladistic analysis. The sexual dimorphism on this ramus primarily consists of a shortening of the outer apical seta of the distal segment.

\section{h. Cristacoxidae Huys}

(53) Spermatophore. All males examined have extremely long and slender spermatophores which generally occupy $1 / 3$ of the complete body length. They also have a curled neck.

(54) Antennula. The first antennular segment possesses an outer spinous process in both sexes.

(55) Antenna. The exopod and the abexopodal seta on the allobasis are missing in the Cristacoxidae.

(56) Mandible. The mandibular palp is uniramous and 2-segmented. It consists of an asetose basis and quadrisetose endopod. The alleged presence (Petkovski, 1977) of an inner seta on the basis of $C$. noodti is an erroneous interpretation of the long spinules found in this position.

(57) Maxilla. The middle (or proximal when only 2 endites) endite on the syncoxa bears a modified claw. This claw exhibits a specialised, swollen tip consisting of fine spinules arranged in a U-shaped excavation, and is confluent at its base with the proper endite.
(58) Protopod P1. The presence of outer cristae on the precoxa and coxa, and the migration of the inner spine to the anterior surface of the basis constitute a double apomorphy for the family.

(59) Exopod P1. The distal exopod segment possesses 4 geniculate setae which increase in length adaxially, compared to the ancestral condition consisting of 2 outer spines and 2 geniculate setae.

(60) Exopod P2-P4. The distal exopod segment is typically equipped with 2 outer spines instead of 3 and moreover these spines are remarkably setiform in appearance.

(61) Exopod P4. The middle exopod segment has lost the inner seta.

(62) Endopod P3-P4. The endopods of P3 and P4 are unisegmented, involving the fusion of both segments with retention of the ancestral proximal setation.

(63) Fifth legs. The fifth legs in both sexes have a neotenous origin (see discussion Cristacoxidae).

\section{i. Concluding remarks}

When generating this cladogram at hand, it was assumed that evolution within the Copepoda has proceeded primarily by oligomerization (Boxshall et al., 1984). Indeed, most clades in the phylogenetic scheme of the Laophontoidea are supported by apomorphies involving fusion and loss of limb segments and loss of setation elements. However, the distinctness of the families and of most of the clades could be reinforced by novel characters such as the pleural glands in the Adenopleurellidae, the lamelliform caudal rami in the Laophontopsidae, the antennular processes and thoracopodal cristae in the Cristacoxidae, the brush setae in the Orthopsyllidae, etc. On the other hand it is shown that armature patterns on all the appendages are highly conservative evolutionary and hence they can provide a great deal of information of phylogenetic significance. The setation of the various mouthparts has often been neglected in the past, but modern, detailed taxonomic descriptions have revealed that 
they provide an as yet unexplored pool of information useful for cladistic analyses. I strongly argue for a detailed approach of harpacticoid morphology avoiding expressions such as "... mouthparts typical of the family ...", and recommend that sexual dimorphism on the thoracopods should be outlined in terms of homology between the sexes.

\section{Acknowledgements}

Grateful thanks are due to Prof. Dr. Jan Stock, University of Amsterdam, for putting at my disposal the material collected in the West Indies (supported by a grant of the Netherlands Committee for the Marine Biological Stations of the Royal Academy of Sciences, Amsterdam) and in the Canary Islands (under NATO Collaborative Grants Programme, Brussels, contract SA.5-2-05, RG 001/88); and to Prof. Dr. August Coomans, State University of Gent, for providing me with specimens from the Galápagos and from the Great Barrier Reef. I also would like to thank Dr. Trajan K. Petkovski, Prirodonaucen Muzej, Skopje, for allowing me to compare his specimens of $C$. noodti with the present material. Dr. Günter Arlt, Wilhelm-PieckUniversity, Rostock is acknowledged for linguistic advice. Part of this research was carried out under EC Science Grant no. ST $2 * 0443$.

\section{References}

Barnett, P.R.O., 1966. The comparative development of two species of Platychelipus Brady (Harpacticoida). In: H. Barnes ed., Some Contemporary Studies in Marine Science: 113-127 (George Allen \& Unwin Ltd., London).

Bodin, P., 1968. Copépodes Harpacticoïdes des étages bathyal et abyssal du Golfe de Gascogne. Mém. Mus. natn. Hist. nat., (n.Sér.) (A) 55(1): 1-107.

Bodin, P., 1972. Copépodes Harpacticoïdes marins des environs de La Rochelle. 3. Espèces de la zone intertidale de FourasNord. Téthys, 3(4): 841-864.

Bodiou, J.-Y. \& J.-C. Colomines, 1988. Harpacticoïdes (Copépodes) des îles Crozet II. Description d'une espèce nouvelle du genre Tapholaophontodes Soyer, 1974. Crustaceana, 55: 104-110.

Boer, P., 1971. Harpacticoid copepods (Crustacea) living in wood infested by Limnoria from northwestern France. Bull. zool. Mus. Univ. Amsterdam, 2: 63-72.

Bowman, T.E. \& L.G. Abele, 1982. Classification of the recent Crustacea. In: L.G. Abele ed., The Biology of Crustacea, 1. Systematics, the fossil record, and biogeography: 1-27 (Academic Press, New York, etc.).

Boxshall, G.A., 1985. The comparative anatomy of two copepods, a predatory calanoid and a particle-feeding mormonilloid. Phil. Trans. r. Soc. London, (B) 311: 303-377.

Boxshall, G.A., F.D. Ferrari \& H. Tiemann, 1984. The ancestral copepod: towards a consensus of opinion at the First Interna- tional Conference on Copepoda. Crustaceana, Suppl. 7: 68-84.

Chislenko, L.L., 1976. Two new species of harpacticids from hyponeuston of Dalneselenetzkaja Bay (Barents Sea). In: Functional morphology, growth and development of invertebrates of sea plankton. Issled. Fauny Morei, 18: 94-101.

Cottarelli, V., 1977. Mexicolaophonte arganoi n. gen. n. sp. di Laophontidae (Crustacea, Copepoda, Harpacticoida) di acque interstiziali litorali Messicane. In: Subterranean fauna of Mexico, 3. Further results of the Italian zoological mission to Mexico, sponsored by the National Academy of Lincei. Quaderni Accad. naz. Lincei, 171: 91-99.

Cottarelli, V., P.E. Saporito \& A.C. Puccetti, 1983. Novolaophonte viatorum n. gen., n. sp. (Crustacea, Copepoda, Harpacticoida) di acque interstiziali litorali del Massachusetts. Cah. Biol. mar., 24: 269-279.

Cottarelli, V., P.E. Saporito \& A.C. Puccetti, 1986. Indolaophonte ramai n. gen. n. sp. (Crustacea, Copepoda, Harpacticoida) di acque interstiziali litorali dell'Isola di Bali (Indonesia). Boll. Mus. civ. Stor. nat. Verona, 12: 273-281.

Dahms, H.-U., 1988. Development of functional adaptation to clasping behaviour in harpacticoid copepods (Copepoda, Harpacticoida). Hydrobiologia, 167/168: 505-513.

Ferrari, F.D., 1984. Pleiotropy and Pleuromamma, the lookingglass copepods (Calanoida). Crustaceana, Suppl. 7: 166-181.

Fiers, F., 1986. Amsterdam Expeditions to the West Indian Islands, Report 48. Harpacticoid copepods from the West Indian Islands: Laophontidae (Copepoda, Harpacticoida). Bijdr. Dierk., 56: 132-164.

Hamond, R., 1970. On a harpacticid copepod of the genus Orthopsyllus Brady \& Robertson from West Runton, Norfolk, England. Crustaceana, 18: 209-217.

Hamond, R., 1973. The harpacticoid copepods (Crustacea) of the saline lakes in southeast Australia, with special reference to the Laophontidae. Rec. Aust. Mus., 28: 393-420.

Hicks, G.R.F., 1988. Systematics of the Donsiellinae Lang (Copepoda, Harpacticoida). J. nat. Hist., 22: 639-684.

Hicks, G.R.F. \& B.C. Coull, 1983. The ecology of marine meiobenthic harpacticoid copepods. Oceanogr. mar. Biol. annu. Rev., 21: 67-175.

Ho, J.-s., 1986. Phylogeny of Cyclopoida. Syllogeus, 58: $177-183$.

Ho, J.-s. \& P.S. Perkins, 1977. A new family of cyclopoid copepod (Namakosiramiidae) parasitic on holothurians from southern California. J. Parasit., 63: 368-371.

Huys, R., 1988a. On the identity of the Namakosiramiidae Ho \& Perkins 1977 (Crustacea, Copepoda), including a review of harpacticoid associates of Echinodermata. J. nat. Hist., 22: 1517-1532.

Huys, R., 1988b. A redescription of the presumed associated Caligopsyllus primus Kunz, 1975 (Harpacticoida, Paramesochridae) with emphasis on its phylogenic affinity with Apodopsyllus Kunz, 1962. Hydrobiologia, 162: 3-19.

Huys, R., 1988c. Stygofauna of the Canary Islands, 10. Rotundiclipeidae fam. nov. (Copepoda, Harpacticoida) from an anchihaline cave on Tenerife, Canary Islands. Stygologia, 4: 42-63. 
Huys, R., in press a. Pholenota spatulifera Vervoort (Copepoda: Harpacticoida): an aberrant laophontid or a specialized diosaccid? J. nat. Hist.

Huys, R., in press b. Adenopleur ella gen. nov., Proceropes gen. nov., Sarsocletodes Wilson (ex Laophontidae) and Miroslavia Apostolov (ex Cletodidae): representatives of a new family (Copepoda: Harpacticoida). J. crust. Biol.

Huys, R., in press c. Marine biological investigations in the Bahamas. Orthopsyllidae fam. nov. (Copepoda: Harpacticoida), a new family of the laophontoidean core. Sarsia.

Huys, R., in press d. Hamondiidae (Copepoda: Harpacticoida), a new family collected from Australian sponges and the status of the Rhynchothalestrinae Lang. Zool. J. Linn. Soc.

Huys, R. \& H. Kunz, 1988. On the generic boundaries within the marine interstitial Latiremidae (Copepoda: Harpacticoida). Stygologia, 4: 292-305.

Huys, R. \& K.A. Willems, 1989. Laophontopsis Sars and the taxonomic concept of the Normanellinae (Copepoda: Harpacticoida): a revision. Bijdr. Dierk., 59: 203-228.

Jakobi, H., 1953. Novos Laophontidae (Copepoda-Crustacea) da costa Brasileira (Neue Laophontiden von der Brasilianischen Kueste). Dusenia, 4: 47-60.

Jakobi, H., 1954. Espécies novas de Harpacticoida (CopepodaCrustacea) encontradas em algas marinhas do litoral ParanáSanta Catarina. Bolm Inst. Oceanogr., S. Paulo, 5: 189-211.

Lang, K., 1944. Monographie der Harpacticiden (Vorläufige Mitteilung), 1-39 (Almqvist \& Wiksells Boktryckeri Ab, Uppsala).

Lang, K., 1948. Monographie der Harpacticiden, 1-1682, tab. I-XXXXVII, maps 1-378, figs. 1-610 (Hảkan Ohlsson, Lund).

Lang, K., 1965. Copepoda Harpacticoida from the Californian Pacific coast. K. svenska VetenskAkad. Handl., (4) 10 (2): 1-560.

Letova, V.N., 1982. Harpacticoida (Crustacea, Copepoda) from the mud-sandy littoral of the East Murman. In: O.A. Skarlato ed., Marine Invertebrates of Coastal Biocenoses of the Arctic Ocean and the Pacific Ocean. Issled. Fauny Morei, 29 (37): 46-75.

Mielke, W., 1975. Systematik der Copepoda eines Sandstrandes der Nordseeinsel Sylt. Mikrofauna Meeresboden, 52: 1-134.

Mielke, W., 1981a. Interstitielle Ectinosomatidae (Copepoda) van Panamá. Mikrofauna Meeresboden, 85: 1-45.

Mielke, W., 1981b. Interstitielle Fauna von Galapagos. XXVIII. Laophontinae (Laophontidae), Ancorabolidae (Harpacticoida). Mikrofauna Meeresboden, 84: 1-106.

Mielke, W., 1982. Three variable Arenopontia species (Crustacea, Copepoda) from Panamá. Zool. Scr., 11: 199-207.

Mielke, W., 1983. Zwei Leptastacus-Arten aus dem zentralen Teil von Panamá. Spixiana, 6: 291-299.

Mielke, W., 1984a. Some remarks on the mandible of the Harpacticoida (Copepoda). Crustaceana, 46: 257-260.

Mielke, W., 1984b. Einige Paramesochridae (Copepoda) von Panamá. Spixiana, 7: 217-243.

Mielke, W., 1985. Interstitielle Copepoda aus dem zentralen Landesteil von Chile: Cylindropsyllidae, Laophontidae, An- corabolidae. Microfauna Marina, 2: 181-270.

Monard, A., 1934. Description de trois Harpacticides marins d'Angola. Revue Zool. Bot. afr., 26: 1-9.

Monard, A., 1935. Étude sur la faune des Harpacticoïdes marins de Roscoff. Trav. Stn biol. Roscoff, 13: 5-88.

Nicholls, A.G., 1944. Littoral Copepoda from the Red Sea. Ann. Mag. nat. Hist., (11) 11: 487-503.

Noodt, W., 1955. Copepoda Harpacticoidea von Teneriffa (Kanarische Inseln). Zool. Anz., 154: 200-222.

Noodt, W., 1958. Die Copepoda Harpacticoidea des Brandungsstrandes von Teneriffa (Kanarische Inseln). Abh. mat.nat. Kl. Akad. Wiss. Mainz, 1958 (2): 53-116.

Pallares, R.E., 1968. Copépodos marinos de la Ría Deseado (Santa Cruz, Argentina). Contribución sistemática-ecológica I. Contrnes cient. Centro Invest. Biol. mar. Buenos Aires, 27: 1-125.

Pallares, R.E., 1975. Sobre un nuevo genero de la familia Laophontidae. Contrnes cient. Centro Invest. Biol. mar. Buenos Aires, 93: 1-5.

Pallares, R.E., 1979. Copépodos Harpacticoides marinos de Tierra del Fuego (Argentina). Isla de los Estados. III. Contrnes cient. Centro Invest. Biol. mar. Buenos Aires, 142: 1-22.

Petkovski, T.K., 1977. Cubanocleta noodti n. gen., n. sp., ein neuer Harpacticoide (Crustacea, Copepoda) aus dem Hyporheal Kubas. Fragm. balc., 10: 57-68.

Por, F.D., 1986. A re-evaluation of the family Cletodidae Sars, Lang (Copepoda, Harpacticoida). Syllogeus, 58: 420-425.

Sars, G.O., 1905. Pacifische Plankton-Crustaceen. (Ergebnisse einer Reise nach dem Pacific. Schauinsland 1896-1897). II. Brackwasser-Crustaceen von dem Chatham-Inseln. Zool. Jb. (Syst.), 21: 371-414.

Sars, G.O., 1909. Copepoda Harpacticoida, XXV \& XXVI. Laophontidae (concluded), Cletodidae (part.). An account of the Crustacea of Norway with short descriptions and figures of all the species, 5: 277-304, pls. 193-208.

Scott, T., 1905. On some new and rare Copepoda from the Scottish seas. Rep. Fishery Bd Scotl., 23: 141-153.

Vervoort, W., 1962. Report on some Copepoda collected during the Melanesia Expedition of the Ôsaka Museum of Natural History. Publs Seto mar. biol. Lab., 10: 393-470.

Vervoort, W., 1964. Freeliving Copepoda from Ifaluk Atoll in the Caroline Islands with notes on related species. Bull. U.S. natn. Mus., 236: i-ix, 1-431.

Wells, J.B.J., 1967. The littoral Copepoda (Crustacea) from Inhaca Island, Mozambique. Trans. r. Soc. Edinburgh., 67: 189-358.

Wells, J.B.J., 1968. New and rare Copepoda Harpacticoida from the Isles of Scilly. J. nat. Hist., 2: 397-424.

Wells, J.B.J., G.R.F. Hicks \& B.C. Coull, 1982. Common harpacticoid copepods from New Zealand harbours and estuaries. N. Z. J. Zool., 9: 151-184.

Received: 11 December 1989 